\title{
An experimental study on the mechanism of degradable fiber-assisted diverting fracturing and its influencing factors
}

Daobing Wang ${ }^{1,2,3} *$, Fujian Zhou ${ }^{1,2}$, Hongkui $\mathrm{Ge}^{1,2}$, Yang $\mathrm{Shi}^{3}$, Xiangyi $\mathrm{Yi}^{4}$, Chunming Xiong ${ }^{3}$, Xiongfei Liu ${ }^{1}$, Yuanqin $\mathrm{Wu}^{4}$, and Ying $\mathrm{Li}^{5}$

1. Unconventional Natural Gas Research Institute, China University of Petroleum, Beijing, China, 102249

2. State Key Laboratory of Petroleum Resources and Prospecting, China University of Petroleum, Beijing 102249, People's Republic of China

3. Beijing Branch, Research Institute of Petroleum Exploration and Development, China National Petroleum Cooperation, Being, China, 100083

4. College of Energy Resources, Chengdu University of Technology, Chengdu, China, 610059

5. Chuanqing Drilling Engineering Company Limited, China National Petroleum Cooperation, Chengdu, China, 610051

*Corresponding author: Daobing Wang

Phone: +86 (010) 8973-9051

Fax: +86(010) 8973-9051

Email: 0546wdb@163.com

\section{Abstract}

Fiber-laden fluid systems have been successfully applied for reorientation fracturing in tight gas and shale gas reservoirs around the world. Although many successful cases have been reported in the literature, there is a lack of a deep understanding of the mechanical mechanism of fiber-assisted diverting fracturing. Hence, this paper presents a systematic study of the fracture diversion mechanisms of the fiber-diverting fracturing technique. A series of laboratory experiments is conducted with a real tri-axial stress simulation system. Degradable fibers are applied to large-size natural outcrop samples $(300 \mathrm{~mm} \times$ $300 \mathrm{~mm} \times 300 \mathrm{~mm}$ ) under true triaxial stress conditions. The dynamic filtration experiment to test the temporary plugging ability showed that the fractures were effectively plugged by fiber fluids. A variety of factors related to the fracture reorientation are tested and compared, including injection rate, fracture width and horizontal principal stress difference. The additional pressure drop caused by the fiber filtration cake is calculated and used to quantitatively analyze the effects on fracture reorientation. The net pressure increase is the driving force of the fracture diversion and formation of the fracture network. The conclusions were used to guide carbonate reservoir stimulations in the Tarim oil field, in northwest China. The phenomenon of fracture diversion was evident as the pumping pressure increased considerably after injecting the degradable fiber. The hydraulic fracturing treatment and production results showed substantial pressure responses and excellent hydrocarbon production.

Abbreviations:

DCF, diverting clean fiber; SRV, stimulated reservoir volume; FDS, fracture diverting system; MTS, material testing system

Keywords: Degradable Fiber; Diverting fracturing; Dynamic filtration; Additional pressure drop; Skin factor; Circumferential stress 


\section{INTRODUCTION}

In recent years, with the accelerated pace of the exploration and development of unconventional hydrocarbon resources, hydraulic fracturing technology has become a worldwide focus. Conventional hydraulic fracturing technology generates only a pair of simple symmetric fractures, which does not enable ultra-low matrix permeability reservoirs to meet the requirements of effective exploration and development. Therefore, the stimulated volume must be expanded to increase the fracture complexity. Threedimensional reconstruction (i.e., 3D fracture network) of the hydrocarbon reservoir is conducted by means of SRV (stimulated reservoir volume) fracturing, with artificial fracture networks generated (Fish, 2012). This technology can maximize the stimulation volume and thereby markedly increase the effective permeability of the reservoir, resulting in increased oil and gas production (Warpinski et al., 2009).

\subsection{Propagation of fracture}

A dominant azimuth of the hydraulic fracture propagation exists in the formation, which is under the control of in situ stresses, natural fractures and other factors (Blanton, 1986; Chen et al., 2000; Yudin et al., 2007; Potapenko et al., 2009; Zhou et al., 2009; Mayerhofer et al., 2010; Allison et al., 2011). The hydraulic fracture propagation direction in the coal rock was random, but the occurrence probability was greater in some directions than in others. This indicates that crack propagation is related to in situ stresses, the local stratigraphic structure and cleats in the coal rock (Shan et al., 2005; Zhang, 2014).

\subsection{Formation of fracture network}

Zhou et al. (2008), Dahi (2009), and Liu et al. (2014) used a true triaxial hydraulic fracturing system to investigate the influence of the natural fracture network on hydraulic fracture propagation in carbonate reservoirs. The results showed that the complexity of the hydraulic fracture was controlled by the net pressure, compressed stress on prefabricated fracture planes, shear strength and cohesion of weak planes.

\subsection{Pore elasticity effect and reorientation}

The formation mechanism of network fracture was investigated in the process of SRV fracturing in shale gas plays (Gale et al., 2007; Heng et al., 2014). A fully coupled finite element numerical simulation method was proposed (Aghighi et al., 2009), taking into account pore elasticity theory. By using this model, how the initiation and propagation of re-fractures was affected by stress disturbances induced by production was investigated in tight gas reservoirs. These disturbances lead to re-fracture reorientation. Re-fracture could be initiated in certain directions with the help of an 
oriented perforation technique. The development of the stratification plane, pump pressure and stress state had a significant impact on the fracture morphology. Jin et al. (2009), Li et al. (2009), Zhang et al. (2010) and Li et al. (2014) simulated hydraulic fracture propagation in fractured vuggy carbonate reservoirs using the damage mechanics method. The results demonstrated that the tortuous diversion conditions of the hydraulic fracture depended on the angle between the maximum horizontal principal stress and natural fracture and the scale of the fracture-cave cube.

\subsection{Conventional diverting agents for fracture diversion}

When objective factors such as stress differences were bad for fracture diversion, an artificial barrier bed could be introduced by temporarily blocking the diverting agent to seal the formed fractures or high-permeability channels to enhance the stimulation effect. Wang et al. (2005) investigated diverting fracturing technology in low-porosity, lowpermeability reservoirs. Natural fractures did not exist in the formation. At the late stage of the stimulation treatment, larger-size proppant or soluble wax balls were pumped. The net pressure increased, forcing artificial fractures to divert in a new direction.

To achieve fracturing diversion, the fluid loss due to natural fractures needs to be reduced by filter reducers. According to the characteristics of fractured reservoirs in the Zhongyuan oilfield, Zhang et al. (2005) analyzed the acting mechanism of a filtrate reducer during the fracturing treatment. They investigated the composition of an oilsoluble filtrate reducer, its synthetic method and performance. At the same temperature and pressure, the amount of fluid loss was reduced by approximately 32\%, a great improvement compared with the loss reduction of approximately $15 \%$ by other reducers (Hofmann et al., 2014). This reducer had the characteristic of adaptive temperature, strong pressure resistance ability, good oil soluble performance and compatibility with the fracturing fluid system, and low damage to the core permeability. Based on analyses of reducing the filter loss of natural fractures by fine pottery clays (Jennings et al., 1990; Zhang et al., 2014), the optimal concentration of fine pottery clays was found to be approximately $10 \% \mathrm{wt}$. They were gradually pumped from small size to larger size. The amount of fluid loss was optimized by fine pottery clays combined with proppant plugs and fracture morphology. Satisfactory results were achieved in the field application.

\subsection{New diverting agents for fracture diversion}

Zhou et al. (2009) used a fiber that is automatically degradable at the formation temperature to temporarily block open fractures and force succeeding fractures to divert in new directions so the probability of connecting the fracture-cave cube could be improved. A good effect was obtained with this technology in field application. 
Potapenko et al. (2009) controlled crack propagation by using a novel degradable fiber as a diverting material. Fracture diversion technology was used in the re-stimulation of a horizontal well in the Barnett shale plays. A FDS (fracture-diverting system) could bridge formed fracture networks. An increasing net pressure was observed during the treatment. Allsion et al. (2011) developed automatically degradable and deformable particles. The diverting agent system consisted of two different size particles and had a density of $1.25 \mathrm{~g} / \mathrm{cm}^{3}$. The lower the density is, the more easily it can be carried in water or slightly viscous fluids. When the pressure reached the critical limit, these particles exhibited deformation. As a tight barrier bed was formed, the fracture permeability became much lower.

General diverting agents such as fine pottery clays and oil-soluble resins caused greater damage to the formation permeability, and they were only used in a limited temperature range (Loiseau et al., 2011). Degradable fibers exhibit many advantages, including high plugging strength, automatic and complete degradation, and negligible damaged to the formation (Saheb and Jog, 1999; Zhou et al., 2009).

Although many successful cases have been reported in the literature, there is a lack of a deep understanding of the mechanical mechanisms of fiber-diverting fracturing. For example, the effect of the injection rate and fiber concentration on fracture redirection is still unclear. Hence, this paper presents a systematic study of the fracture diversion mechanisms of the fiber-diverting fracturing technique.

\section{MECHANICAL MECHANISM OF FRACTURE DIVERSION}

The mechanical mechanisms of fiber-assisted fracture diversion include the following three main scenarios:

(a) Single crack propagation condition: The fiber can effectively seal the open mouth or tip of pre-existing fractures, forming a tight fiber cake. This mainly demonstrates that (1) fiber fluids can reduce fluid loss and make it difficult for the fluid pressure to transfer to the fracture tip. Therefore, the fluid pressure transmission efficiency is reduced and (2) an artificial barrier bed can be formed by adding a temporary blocking diverting agent to increase the fracture toughness, thereby sealing and passivating the fracture front ( $\mathrm{Li}$ et al., 1984\&1986; Lu et al., 1995), making it difficult for the fracture to propagate forward, as shown in Fig. 1a.

(b) Competitive cracking under the condition of multiple fractures: When multiple fractures exist near the wellbore or in a major fracture, some of them will be selectively blocked by fiber fluids. These blocked fractures have different fracturing pressures. After injecting the fracturing fluids, the net pressure in them will gradually increase. If the pump pressure reaches the minimum fracturing pressure, a new fracture will initiate and 
propagate from existing fractures or weak planes. With the further increase of the pump pressure, another new fracture will initiate and extend, which is called the second fracturing pressure. The fiber can increase the net pressure in the fracture by more than 3 MPa (Potapenko et al., 2009; Zhou et al., 2009), which forces new fractures to propagate in a new direction, as shown in Fig. $1 b$.

(c) Fracture diversion in nonhomogeneous and anisotropic rock: The fiber can effectively seal formed cracks. When the net pressure reaches a critical value and factors such as local stress fields and weak planes meet certain mechanical conditions, new fractures will be generated. The artificial fracture orientation is changed (Weng et al., 2011; Jiang et al., 2011; Nicolas, 2011; Soliman et al., 2011), as shown in Fig. 1c. Increasing the net pressure inside the fracture drives the fracture diversion and fracture network formation. The net pressure of fracture propagation is associated with the stress difference. Its basic principle is that (assuming that the overburden stress is dominant in these cases) if the net pressure of fracture extension is larger than the difference between the two horizontal principal stresses, branch fractures will continue to extend along natural fractures, ultimately forming a crisscross network fracture system dominated by the major fracture. The natural fracture dip, horizontal stress difference and net pressure have significant impacts on the initiation angle of new fractures. When the horizontal stress difference is small, it is easy to initiate fractures in new directions. The distribution of natural fractures has an important impact on the net pressure at the fracture mouth. The impact of the local tectonic stress state on hydraulic fracture extension is greater than that on natural fractures (Dahi et al., 2011; Zhou et al., 2007, 2008 \& 2010; Cheng et al., 2014). Induced stress and the stress interference of multiple fractures can make a fracture divert, resulting in a stress concentration phenomenon near an artificial fracture. The closer the artificial fracture spacing is, the stronger the induced stress and stress interference, which causes the stress field to redistribute. Then, the difference between the two horizontal principal stresses will become smaller. When the fractured well is restimulated, by optimizing the operating parameters, the existing artificial fractures can be diverted in new directions (Jiang et al., 2011; Warpinski et al., 1989). Therefore, the main impacting factors of fracture diversion in nonhomogeneous and anisotropic rock are the plugging efficiency, net pressure, and anisotropy and heterogeneity of reservoirs.

\section{EXPERIMENTAL SETUP AND PROCEDURE}

Fluid preparation: (1) slick water is composed of $0.3 \% \mathrm{wt}$ general guar in distilled water; its apparent viscosity is $20 \mathrm{mPa} \bullet \mathrm{s}$, as measured by a rotational viscometer; (2) fiber gel is composed of DCF (diverting clean fiber) with $0.8 \%$ wt cross linker YP-150.

To physically simulate the dynamic filtration process and temporary plugging ability at different fracture width levels, corresponding experimental programs are designed. As 
shown in Fig 2a, we use core samples including fractures or similar parts to simulate different fracture widths. To prevent thin pipelines from blocking in the process of fiber injection, higher concentrations of fiber are prepared to uniformly add into the fiberslurry pot in advance. In the experiment, a high-pressure pump displaces the fiber to simulate the real process in the oilfield. This experimental procedure is as follows: (1) measure the dynamic filtration coefficients at different levels of fracture width when the core samples are contacted with slick water at a certain pump rate and rotational speed; (2) measure the dynamic filtration coefficients at different levels of fracture width when the core samples are contacted with DCF at the same pump rate and rotational speed; (3) when full blockage is achieved, test the fracture conductivity of the core samples containing fiber cake; (4) open the core sample, observe the fiber cake and measure its invasion length.

To simulate fracture diversion in the fracturing treatment, we design an experimental program of physical simulation of fibers temporarily plugging diverting fracturing. The fiber-assisted diverting fracturing mechanism will be well simulated at different levels of horizontal stress difference. This experiment uses the MTS true tri-axial fracturing simulation system at a larger scale. The system consists of a confining pressure system (MTS servo supercharger), a true tri-axial device system, a pumping system (highpressure displacement pump), and an output system, as shown in Fig. 2b. A $300 \mathrm{~mm} \times 300$ $\mathrm{mm} \times 300 \mathrm{~mm}$ natural outcrop rock sample is used to simulate the fracturing process (Shi et al., 2013). This experimental procedure is as follows: (1) apply the corresponding confining pressure on six planes of the block: vertical stress $\sigma_{\mathrm{V}}$, maximum horizontal principal stress $\sigma_{\mathrm{H}}$, and minimum horizontal principal stress $\sigma_{\mathrm{h}}$; (2) The first fracturing: At a certain injection rate, the fracturing base fluid is injected to form a fracture; observe the formed fracture morphology; (3) The second fracturing: At a certain injection rate, DCF (diverting clean fiber) is pumped in to seal the formed fracture. With the increase of the injection pressure, new fractures are formed in a certain direction. After several cycles of fiber blockage and new fracture formation, a fracture network at different azimuths will be produced; (4) Open the block and observe the fracture morphology.

\section{EXPERIMENTAL RESULTS AND ANALYSIS}

\subsection{Experimental Results}

(a) Experiment of fiber dynamic filtration

Core samples with different fracture widths are selected. The filtration of slick water and DCF results are obtained for each sample, with the filtration curves of core sample \#1 shown in Fig. 3 and the fluid loss coefficients of each sample shown in Table 1 (Economides et al., 2003). 
The fluid loss coefficient of slick water is 1.6-3.66 times that of DCF. This indicates that the fiber can effectively plug artificial fractures, lowering the permeability near their open mouths and favoring fracture diversion. The larger the fracture width is, the greater the fluid loss coefficient of the DCF is (Zhou et al., 2014).

After the dynamic filtration experiment, each sample is taken out to observe the formation of the fiber cake, as shown in Fig. 4. Core sample \#2 forms a good fiber cake, and core sample \#3 is the second thickest. Because of the narrow fracture width of core sample \#1, the fiber cannot easily enter the fracture. Therefore, fiber cake is not observed in sample \#1. Core sample \#4 has a much greater fracture width $(3 \mathrm{~mm})$, and its fracture wall surface is smooth, as shown in Fig. 5, so it does not easily form a fiber cake. It is clear that the fiber has difficulty in forming a cake near the fracture mouth when its fracture width is below a critical value. In this case, a poor fiber cake is often obtained. When fiber seals a wide fracture, the natural fracture has little impact on the sealing process. When the fracture width is much greater; it is very difficult to seal it. This indicates that there is an optimal match between the fiber and fracture. The fiber length, concentration and gradation have a significant impact on the effective sealing of the fracture (Zhou et al., 2014).

The fiber cake permeability is $1349.2 \times 10^{-3} \mu^{2}$ according to experimental data shown in Table 1. Due to its small amount of fiber cake, core sample \#3 has great fracture conductivity. When the fracture conductivity test is conducted, the liquid takes the fiber cake away, so it is not listed in Table 1. Core sample \#4 hardly forms a fiber cake, so no fracture conductivity experiment was conducted. After the fracture conductivity experiment, each core sample is opened to observe the fiber cake performance, as shown in Fig. 5. Core sample \#2 forms a good fiber cake, which enters approximately $2 \mathrm{~cm}$ from the fracture mouth, while core sample \#1 does not form a fiber cake. Because core sample \#3 has a greater width than \#2, fiber cake is taken away by the fluid. No fracture conductivity test was conducted on core sample \#4. There is small amount of fiber cake when it is opened, which corresponds to Fig. 4.

(b) Experiment of temporary blockage ability at different fracture width levels

The core samples, as shown in Fig. 6a, are loaded into the experimental device, as shown in Fig. 2a. When the fracture wall is a flat plane, a steel piece of special size is embedded into the core to maintain a certain fracture width after applying the confining pressure. When the confining pressure reaches $20 \mathrm{MPa}$, DCF is pumped into the fracture. After the temporary blockage occurs, it is still pumped and pressurized to achieve the final blockage state and invasion length of fiber cake in the fracture. The maximum injection pressure is controlled to be less than $20 \mathrm{MPa}$. The results after reaching the temporary blockage state are as shown in Fig. 6b. A fracture of $0.5-\mathrm{mm}$ width can be plugged, and 
the invasion length of fiber is very short, generally $2-3 \mathrm{~mm}$. When the injection pressure is $18-19 \mathrm{MPa}$, the blockage state cannot be broken.

This experiment simulates the invasion length of fiber cake at five different width levels of $0.5 \mathrm{~mm}, 0.8 \mathrm{~mm}, 1.0 \mathrm{~mm}, 1.3 \mathrm{~mm}$ and $2.0 \mathrm{~mm}$. As shown in Fig. 7, their relationship equation is as follows,

$$
\mathrm{y}=6.096+2.464 \ln (\mathrm{x}-0.267)
$$

where $\mathrm{x}$ denotes the fracture width, $\mathrm{mm}$, and $\mathrm{y}$ denotes the fiber cake invasion length in the fracture, mm.

We design two arrays of experimental programs to simulate the blockage ability at different fracture width levels. The simulated fracture height is $20 \mathrm{~mm}$. The injection concentration of fiber is $1 \% \mathrm{wt}$, and its pumping rate is $0.5 \mathrm{~mL} / \mathrm{min}$. The fracture widths in the first and second arrays of experiments are, respectively, $2 \mathrm{~mm}$ and $3 \mathrm{~mm}$. The inlet pressure change in the injection process is as shown in Fig. 8. For the fractures of $2 \mathrm{~mm} 3$ $\mathrm{mm}$ width, the injection pressure increases to 8-10 $\mathrm{MPa}$ and 4-8 $\mathrm{MPa}$, respectively. This indicates that the DCF can significantly increase the pressure resistance to fluid, favoring a smaller width.

By means of a series of experiments under conditions of different fracture widths and rates, the critical fiber concentration is determined when the blockage is just formed, as shown in Fig. 9. The results show that (1) At the same fracture width, with the increase of the pumping rate, the fiber concentration required to block fracturing increases; (2) At the same pumping rate, with the increase of the fracture width, the required fiber concentration also increases. These findings indicate that when the pumping rate and fracture width increases, it is much more difficult to block the fracture. When the fracture width is $6 \mathrm{~mm}$ or $4 \mathrm{~mm}$, although a higher fiber concentration (more than $2 \% \mathrm{wt}$ ) is adopted, it is very difficult to block the fracture. The pumping rate is $0.5 \mathrm{~mL} / \mathrm{min}$ for a fracture height of $20 \mathrm{~mm}$. If converted to formation scale for a $20-\mathrm{m}$ height in the application, the equivalent rate is approximately $500 \mathrm{~mL} / \mathrm{min}$. Because a blockage is difficult to form at higher pumping rates, it should be less possible for a high pumping rate (more than $500 \mathrm{~mL} / \mathrm{min}$ ) to achieve a good blockage state in field applications. At the same pumping rate, the real fracture width is generally less than $6 \mathrm{~mm}$. This indicates that in a real field application, a fracture of a larger width cannot easily achieve a blockage state, which hinders fracture diversion. In this case, fine pottery clays can be used to bridge larger fractures (Wang et al., 2005; Powell et al., 2007), and then fiber is added to completely block the fracture.

(c) Physical simulation experiment of diverting fracturing Sandstone \#2 (tight sandstone core sample): The sandstone outcrop block is from Xinjiang Province, in northwest China. The cubic sample is $300 \mathrm{~mm} * 300 \mathrm{~mm} * 300 \mathrm{~mm}$ in size. 
The applied stresses in three directions are a maximum horizontal principle stress of 7.5 MPa, a minimum horizontal principle stress of 5.0 MPa, and a vertical stress of 15 $\mathrm{MPa}$. The pumping procedures are composed of two stages of fracturing. The fracturing fluids are pumped along the artificial wellbore during the first fracturing. Then, the injection ceases, and the core sample is opened to observe the fracture morphology. Before the second fracturing, the same stress in three directions is reloaded. The fiber fluids (DCF) are pumped during the second fracturing. The curves of the pump pressure during the two stages are as shown in Fig. 10a, and the new fracture morphologies during the two stages are as shown in Fig. 10b-e.

During the first fracturing, the pump pressure suddenly decreases from $9 \mathrm{MPa}$ to 2 $\mathrm{MPa}$, which demonstrates that core sample \#2 is fractured. After the first fracturing, a single fracture in the east is observed along the maximum horizontal stress direction.

During the second fracturing, DCF is pumped at a rate of $10 \mathrm{~mL} / \mathrm{min}$. In the course, the pump pressure fluctuates several times. At last, the pump pressure suddenly decreases from 52.8 $\mathrm{MPa}$ to $2 \mathrm{MPa}$, and a bell-like ring is emitted, indicating that a new fracture is generated. After the second fracturing process, new artificial fractures, approximately perpendicular to the first fracture, are formed. This indicates that the fiber has a clear temporary plugging effect.

In addition, the fracture diversion mechanisms of limestone outcrops are physically simulated at different levels of horizontal stress difference: 2.5 MPa, 5.0 MPa, 7.5 and $\mathrm{MPa}$. They contain natural fractures. The results are shown in Fig. 11a-f. When the stress difference is $2.5 \mathrm{MPa}$, the fractures in the two fracturing processes are almost normal. When the stress difference is $5.0 \mathrm{MPa}$, the angle between the fractures in the two processes are almost 45 degrees. When the stress difference is $7.5 \mathrm{MPa}$, fracture diversion is not observed (Shi et al., 2013).

From the above experimental results, the fiber has a clear temporary plugging effect that can effectively block old or open fractures. When stress difference is below the critical limit, it is difficult to observe fracture diversion even if a large amount of fiber is continuously pumped. In the process of the fracturing simulation, the pump pressure fluctuates several times, which indicates that the DCF can form many ruptures and undergo fracture propagation processes.

\subsection{Analysis and Discussion}

\subsubsection{Influencing factors of plugging efficiency}

After the filled zone formation of the fiber cake, because the fiber-filled zone permeability is far below the open fracture permeability, the subsequent fluid is resisted into fracture. It is equivalent to forming a skin factor of the fiber cake $S_{\text {fiber }}$, so an additional pressure drop across the filled zone is calculated, termed as $\Delta \mathrm{P}_{\text {fiber }}$. According to the skin factor equation of the fracture cake (Jamiolahmady et al., 2007) and fracture width (Economides et al., 2003; Morita et al., 1990), we can calculate the additional pressure drop at the fracture mouth when fracturing fluid is injected. The influential factors of plugging efficiency and their laws are obtained, as shown in Fig. 12a-b (Wang, 2013).

(a) Influence of pump rate on additional pressure drop: at a constant viscosity, the lower the pump rate is, the larger the additional pressure drop is. If the pump rate is more than 
$1.6 \mathrm{~m}^{3} / \mathrm{min}$, the additional pressure drop diminishes. With the increase of the viscosity of the fracturing fluid, the additional pressure drop gradually grows.

(b) Influence of artificial fracture width on additional pressure drop: at a constant viscosity level, the greater the artificial fracture width is, the smaller the additional pressure drop is. When the fracture width exceeds $4 \mathrm{~mm}$, the additional pressure drop is also reduced. With the increase in the viscosity of the fracturing fluid, the additional pressure drop also gradually grows.

The results of the numerical simulation are consistent with the experimental results in Section 4.1 (Wang, 2013; \& Zhou et. al, 2014). Therefore, it is recommended that DCF be pumped at a low rate in field applications. Then, fracturing fluid with a high viscosity is injected to increase the additional pressure drop. These can keep the artificial fracture width small, enhancing the sealing efficiency of the DCF and thereby achieving superior fracture diversion.

(c) Influence of bottom hole pressure increase on sealing efficiency: The bottom hole pressure increase depends on the accumulated volume of fluids. With the increase of the fiber fluid volume, the bottom hole pressure gradually increases. After forming the fiber cake at the fracture mouth, the fracture permeability will sharply decrease, which increases the bottom hole pressure. If the bottom hole pressure is sufficiently high, the fracture tip can propagate forward. At this time, it is required to form a new fiber filter cake so that the pressure behind the fiber cake is less than the fracture extension pressure, so that the fracture can be sealed. According to the fracture propagation rule, the condition of the fracture extension forward of a PKN-type fracture is (Wan et al., 1998)

$$
\begin{gathered}
K_{I}=\frac{p_{n e t} h_{f}}{2 E_{(k)}} \sqrt{\pi / L} \geq K_{I C} \\
E_{(k)}=\int_{0}^{\pi / 2}\left(\sin ^{2} \beta+\frac{L_{f}{ }^{2}}{h_{f}{ }^{2}} \cos ^{2} \beta\right)^{1 / 2} d \beta \\
p_{n e t}=\left(\frac{E^{\prime 3}}{h_{f}{ }^{4}} \mu q L\right)^{1 / 4}
\end{gathered}
$$

where $p_{n e t}$ denotes the net pressure in the fracture (Economides et al., 2003), MPa; $h_{f}$ denotes the fracture height, $m ; K_{I}$ denotes the stress intensity factor of either tip, $\mathrm{MPa} \bullet \mathrm{m}^{1 / 2} ; \mathrm{K}_{\mathrm{IC}}$ denotes the fracture toughness, MPa $\bullet \mathrm{m}^{1 / 2}$ (limestone fracture toughness is equal to $\left.0.5 \mathrm{MPa} \cdot \mathrm{m}^{1 / 2}\right) ; \mathrm{E}(\mathrm{k})$ denotes the integral coefficient of the tensile fracture; $\mathrm{L}$ denotes the effective fracture length, which is equal to the original crack length minus the length of the fiber cake; $E^{\prime}=E /\left(1-v^{2}\right), E$ denotes the elastic modulus, MPa; $v$ denotes the Poisson ratio; $\mu$ denotes the fluid viscosity, $\mathrm{mPa} \cdot \mathrm{s}$; and $\mathrm{q}$ denotes the injection rate, $\mathrm{m}^{3} / \mathrm{s}$. 
According to the net pressure equation (Economides et al., 2003), combined with equation (1), the relationship curve between the bottom hole pressure and the length of the filter cake is obtained, as shown in Fig. 12c. With the increase of the bottom hole pressure, the required fiber length of the filter cake also increases, with a good linear relationship.

(d) Horizontal stress difference

According to the theory of stress fields induced by fluid injection and artificial fractures (Warpinski and Branagan, 1989; Raz et al., 2011), the diverting radius (the corresponding y coordinate when the circumferential stress reaches the far field stress on the map) curves at different viscosity and stress difference levels are obtained (Wang et al., 2015), as shown in Fig. 13. The smaller the horizontal principal stress difference is, the larger the diverting radius is. When the stress exceeds 7-8 $\mathrm{MPa}$, the diverting radius is close to zero, which indicates that it is difficult to divert.

(e) Net pressure

By the analytical solutions of stress fields induced by 2D vertical fractures (Warpinski et al., 1989; Jiang et al., 2011), the main controlling factors (net pressure and induced stress field in major fracture) of network fractures in shale gas plays are simulated (Wang et al., 2015a \& 2015b). The results demonstrate that the net pressure in a major fracture can be high enough (higher than the sum of the horizontal difference stress and tensile strength) to achieve fracture diversion (Cai et al., 2012; Weng et al., 2011). According to the Mohr-Coulomb principle, enhancing the net pressure in the fracture can be approximately considered as increasing the pore pressure (assuming that fluid leak-off can be ignored in tight gas reservoirs). Therefore, the effective stress decreases and the radius of the Mohr circle decreases (moving towards the origin). This leads to the redistribution of the shear stress field, promoting fracture diversion. The experiment of the fiber temporary blockage ability demonstrates that the fiber can greatly improve the net pressure in the fracture. Therefore, increasing the net pressure is the key to fracture diversion and fracture network formation (Kresse et al., 2013; Rutqvist et al., 2015; Cai et al., 2012; Jiang et al., 2011).

\subsubsection{Mechanism of fiber degradation}

It is essential for the fiber to be completely degradable at a certain temperature. The mechanism of fiber degradation is investigated in the laboratory. According to the degradation temperature, the fibers can be divided into three types: $90^{\circ} \mathrm{C}$ fiber, $120^{\circ} \mathrm{C}$ fiber and $150^{\circ} \mathrm{C}$ fiber. For each type of fiber, its degradation experiment is respectively conducted at $90^{\circ} \mathrm{C}, 120^{\circ} \mathrm{C}$ or $150^{\circ} \mathrm{C}$. Their degradation curves are shown in Fig. 14a-14c. After $5 \mathrm{~h}$, their degradation rates can be more than $85 \%$. This indicates that they have a 
good degradation effect and can be automatically and completely degraded at the reservoir temperature.

\section{FIELD APPLICATION}

For heterogeneous carbonate reservoirs, if the maximum horizontal principal stress direction, natural fracture orientation, and heterogeneous reservoir body are not well matched during the acid fracturing treatment and it is possible to form a diversion fracture (small horizontal principal stress), a high concentration of fiber can be used to temporarily block or open old fractures. The injection pressure will be increased, forcing the fracture to initiate and propagate along another direction. In this manner, it is likely to enhance the connectivity with the reservoir body and improve the acid fracturing effect. In the process of the fiber-assisted diverting acid fracturing treatment, the fiber temporary blockage and diverting efficiency are enhanced by means of a low pumping rate to fill the fracture, increasing the net pressure in the fracture and temporarily plugging it several times (Zhou et al., 2009). HPHT (high- pressure, high-temperature) carbonate reservoirs in the Tarim Basin have the characteristics of strong heterogeneity, different natural fracture and cave distributions and strong stress anisotropy. To improve the stimulation effect, fiber-assisted diverting acid fracturing technology is applied in 85 wells. Among these wells, the greatest diverting pressure is almost $40 \mathrm{MPa}$, while the smallest is $5 \mathrm{MPa}$. There is a special case in that reference (Zhou et al., 2009). The average previous oil production rate is lower than 10 tons per day, and the current production rate is generally more than 80 tons per day. In this manner, the production enhancement effect is obvious.

Case study: Well YM204 is an appraisal well located in the large Yingmai 2 anticline structure of the Nanka-Yingmaili low uplift of the North Tarim Uplift in the Tarim Basin. Drilling and mud logging results demonstrate less oil and gas production; the real borehole trajectory deviates from the reservoir body with high-amplitude and abnormal seismic reflection (Zhou et al., 2009). Seismic data interpretation reveals that the distance between the target interval and the middle part of the reservoir body is approximately 150 meters. After the casing perforation completion, well testing shows that there is only a small amount of oil produced for $36 \mathrm{~h}\left(0.2 \mathrm{~m}^{3}\right)$. The shut-in curve reflects that the reservoir near the wellbore is very tight. However, the tendency of the pressure derivative curve in the later period is falling and flattening, which indicates that there is a good reservoir body far from the wellbore. Although the horizontal principal stress orientation is good for acid fracturing, the orientation of natural fractures is bad for connecting the reservoir body, and the reservoir body is distant from the wellbore. Therefore, the fiber-assisted diverting fracturing technology is adopted to improve the connectivity with the fracture-cave cube and enlarge the stimulation range. 
After the first fracturing, there is no obvious communication shown; in the second fracturing, the pump pressure increases to $5.8 \mathrm{MPa}$ when the DCF arrives at the fracture mouth. The pump pressure in the second fracturing is $14 \mathrm{MPa}$ higher than that in the first fracturing. This clearly indicates the presence of fracture. In the later period, there is obvious communication shown. Analysis suggests that the strong amplitude area has been communicated (pump pressure remarkably decreases). After injecting the acid fluid, the pump pressure decreases by more than $15 \mathrm{MPa}$, indicating the clear communication effect (Zhou et al., 2009).

After the acid fracturing treatment, the broken fracturing fluid is flown back with $6 \mathrm{~mm}$ choke. The daily oil output is $100 \mathrm{~m}^{3}$ per day, and the gas output is $11000 \mathrm{~m}^{3}$ per day. According to the well testing curves in the post-fracturing, the slope of the double logarithmic diagnosis curve is $1 / 2$. This indicates the linear flow regime of the hydraulic fractured well, which indicates that the well was successfully hydraulically fractured. In the late period of the double logarithmic diagnosis curve, the slope declines, showing that the hydraulic fracture has communicated a favorable reservoir body (Zhou et al., 2009; Wang et al., 2015).

\section{CONCLUSIONS}

This paper investigates the mechanical mechanism of degradable fiber-assisted diverting fracturing by means of a systematic experimental study. The following conclusions can be made:

1. The experimental results of the dynamic filtration of fiber and true tri-axial physical simulation demonstrate that two types of mechanical mechanisms of degradable fiber-assisted diverting fracturing exist. Plugging old or open fractures leads to increasing the treatment pressure. A higher treatment pressure means increasing the fracture pressure. Under the same closure stress, the net pressure increases, and this is considered a second mechanism. It is also the core for the diversion of the fracture and the formation of a fracture network.

2. The main influencing factors that affect degradable fiber-assisted diverting fracturing include the horizontal principal stress difference, fracture width, heterogeneity and anisotropy of reservoir, fiber concentration, fluid viscosity and pumping rate. The critical stress difference is $7.5 \mathrm{MPa}$. This is favorable for diverting fracturing under the conditions of a smaller horizontal principal stress difference, smaller fracture width (less than $6 \mathrm{~mm}$ ), higher fiber concentration (greater than $1 \% \mathrm{wt}$ ), higher fluid viscosity, lower pumping rate (lower than 1.6 $\mathrm{m}^{3} / \mathrm{min}$ ) and higher net pressure. With the increase of the bottom hole pressure, the required fiber length of the filter cake also increase. They have a good linear relationship. 
3. After $5 \mathrm{~h}$, the fiber degradation rate can be more than $85 \%$ in the laboratory. This indicates that they have a good degradation effect. They can be automatically and completely degradable at reservoir temperature.

4. The conclusions are used to guide carbonate reservoir stimulation in the Tarim oil field, in northwest China. The phenomenon of fracture diversion is evident, as the pumping pressure increased considerably after injecting DCF. The initial results indicate substantial pressure responses and excellent oil and gas production.

$\begin{array}{ll}\text { Nomenclature and units } \\ K_{\mathrm{IC}} & \text { critical fracture toughness, } \mathrm{MPa} \cdot \mathrm{m}^{0.5} \\ K_{\mathrm{I}} & \text { fracture toughness, } \mathrm{MPa} \cdot \mathrm{m}^{0.5} \\ p_{\text {net }} & \text { net pressure in the fracture, } \mathrm{MPa} \\ \Delta P_{\text {fiber }} & \text { additional pressure drop of fiber cake, } \mathrm{MPa} \\ \Delta S_{\mathrm{fiber}} & \text { skin factor of fiber cake, dimensionless } \\ h_{\mathrm{f}} & \text { fracture height, } \mathrm{m} \\ E(k) & \text { integral coefficient of tensile fracture, dimensionless } \\ L & \text { half-fracture length, } \mathrm{m} \\ \mu & \text { apparent viscosity, } \mathrm{mPa} \cdot \mathrm{s} \\ w_{\mathrm{f}} & \text { fracture width, } \mathrm{m} \\ \sigma_{\mathrm{H}} & \text { the maximum horizontal principle stress, } \mathrm{MPa} \\ \sigma_{\mathrm{h}} & \text { the minimum horizontal principle stress, MPa } \\ \Delta \sigma & \text { horizontal principal stress difference, } \mathrm{MPa} \\ T & \text { tensile strength, } \mathrm{MPa} \\ P_{1}, P_{2}, P_{3} & \text { fracturing pressure, } \mathrm{MPa}\end{array}$

\section{ACKNOWLEDGMENTS}

The authors would like to give our sincere gratitude to the precious financial support from China's Ministry of Science and Technology (973 program, Grant No. 2015CB250903), National Science Foundation of China (Grant No. 51490652 and 41304141), China National Petroleum Cooperation (Scientific Research and Technological Development Project, Grant No. 2010E-2105 and 2014A-4212), China Petrochemical Corporation ("Micro-Nano capillary imbibition and damage mechanisms of unconventional hydrocarbon reservoirs" Project), Chinese Academy of Sciences (Strategic Leading Science and Technology Project, Grant No. XDB10050203), as well as China University of Petroleum(Beijing) scientific research fund(Grant No.YJRC2013-17). 


\section{REFERENCES}

Aghighi, M. A., Rahman, S. S., \& Rahman, M. M. 2009. Effect of formation stress distribution on hydraulic fracture reorientation in tight gas sands. Asia Pacific Oil and Gas Conference \& Exhibition, Jakarta, Indonesia. Society of Petroleum Engineers. Paper SPE-122723-MS.

Allison, D., Curry, S., \& Todd, B. 2011. Restimulation of Wells using Biodegradable Particulates as Temporary Diverting Agents. Canadian Unconventional Resources Conference, Calgary, Alberta. Society of Petroleum Engineers. Paper CSUG/SPE149221-MS.

Blanton, T. L. 1986. Propagation of hydraulically and dynamically induced fractures in naturally fractured reservoirs. SPE Unconventional Gas Technology Symposium, Louisville, Kentucky. Society of Petroleum Engineers. Paper SPE SPE-15261-MS.

Cai B., Ding Y. H., \& Lu Y. J., et al. 2012. Study and application of new in-fissure fracturing technique for improving stimulated reservoir volume. Petroleum Geology and Recovery Efficiency, 19(5): 108-110, 118.

Chen M., Pang F., \& Jin Y.. 2000. Experiments and Analysis on Hydraulic Fracturing By a Large-size Triaxial Simulator. Chinese Journal of Rock Mechanics and Engineering, 19: 868-872.

Cheng Y.F., Chang X., \& Sun Y.W., et al. 2014. Research on fracture network propagation pattern of shale reservoir based on fracture mechanics. Natural Gas Geoscience, 25(4): 603-611.

Dahi T. A. 2009. Analysis of hydraulic fracture propagation in fractured reservoirs: an improved model for the interaction between induced and natural fractures. $P h D$ Dissertation, The University of Texas at Austin, USA.

Dahi T. A., \& Olson J. E. 2011. Numerical modeling of multistranded-hydraulic-fracture propagation: Accounting for the interaction between induced and natural fractures. SPE Journal, 16(3): 575-581. Society of Petroleum Engineers. Paper SPE-124884PA.

East J. L., Soliman, M. Y., \& Augustine, J.. 2011. Methods for enhancing far-field complexity in fracturing operations. SPE Production and Operations, 26(3), 291. Society of Petroleum Engineers. Paper SPE-133380-PA.

Economides, M.J., \& Nolte, K.G., 2003. Reservoir Stimulation, Third ed. John Wiley \& Sons. Inc, New York.

Fish, A. M., 2012. Microseismic velocity inversion and event location using reverse time imaging. PhD dissertation, Colorado School of Mines, USA.

Gale, J. F., Reed, R. M, \& Holder, J.. 2007. Natural fractures in the Barnett Shale and their importance for hydraulic fracture treatments. AAPG bulletin, 91(4): 603-622. 
Heng S., Yang C.H., \& Zeng Y.J., et al. 2014. Experimental study on the hydraulic fracture geometry of shale. Chinese Journal of Geotechnical Engineering, 36(7), 1807-1816.

Hofmann, H., Babadagli, T., \& Zimmermann, G. 2014. Numerical simulation of complex fracture network development by hydraulic fracturing in naturally fractured ultratight formations. Journal of Energy Resources Technology, 136(4): 042905.

Jamiolahmady, M., Danesh, A., Tehrani, DH, \& Mahdiyar, H. 2007. New Mechanical and Damage Skin Factor Correlations for Hydraulically Fractured Wells. European Formation Damage Conference, Scheveningen, The Netherlands. Society of Petroleum Engineers. Paper SPE-107634-MS.

Jennings Jr, A. R., \& Stowe, L. R. 1990. U.S. Patent No. 4,892,147. Washington, DC: U.S. Patent and Trademark Office.

Jiang T.X., Jia C.G., \& Wang H.T., et al. 2011. Study on network fracturing design method in shale gas. Petroleum Drilling Techniques, 39(3): 36-40.

Kresse, Olga, Weng, Xiaowei, Gu, \& Hongren, et al. 2013. Numerical modeling of hydraulic fractures interaction in complex naturally fractured formations. Rock mechanics and rock engineering, 46(3): 555-568.

Li B.Y.. 1984. The discussion on vertical fracture height in the course of hydraulic fracturing. Oil Drilling \& Production Technolog, 5: 43-49.

Li B.Y., Li H.J.. 1986. The discussion on vertical fracture height again in the course of hydraulic fracturing. Oil Drilling \& Production Technology, 1: 67-74.

Li L.D., Zhang S.C., \& Zhang J., et al. 2009. Mechanism of hydraulic fracture propagation in fracture-cavity carbonate reservoirs. Acta Petrolei Sinica, 30(4): 570573.

Li, S., Kang, Y., You, \& L., Li, D, et al. 2014. Experimental and Numerical Investigation of Multiscale Fracture Deformation in Fractured-Vuggy Carbonate Reservoirs. Arabian Journal for Science and Engineering, 39(5), 4241-4249.

Loiseau, A., Chen, Y., \& Panga, M. K., 2011. U.S. Patent Application 13/294,297.

Lu X.F. Liu F.Q. \& Han Z.H.. 1995. Artificial control technique of vertical extension of fracture in hydraulic fracturing. Oil Drilling \& Production Technolog, 17(1): 82-89.

Liu Z.Y., Chen M., \& Zhang G.Q.. 2014. Analysis of the influence of a natural fracture network on hydraulic fracture propagation in Carbonate Formations. Rock mechanics and rock engineering, 47(2): 575-587.

Mayerhofer, M. J., Lolon, E.P., \& Warpinski, N. R., et al, Claude M. 2010. What is stimulated reservoir volume? SPE Production and Operations, 25(1), 89-98. Society of Petroleum Engineers. Paper 119890-PA.

Morita, N. B., AD, \& Guh, G.F.. 1990. Theory of lost circulation pressure. SPE Annual Technical Conference and Exhibition, New Orleans, Louisiana. Society of Petroleum Engineers. Paper SPE-20409-MS. 
Potapenko, D. I., Tinkham, S. K., \& Lecerf, B.,et al. 2009. Barnett Shale refracture stimulations using a novel diversion technique. SPE Hydraulic Fracturing Technology Conference, The Woodlands, Texas. Society of Petroleum Engineers. Paper SPE-119636-MS.

Powell, A., Bustos, O., \& Kordziel, W., et al. 2007. Fiber-laden fracturing fluid improves production in the Bakken shale multilateral play. Rocky Mountain Oil \& Gas Technology Symposium, Denver, Colorado, U.S.A. Society of Petroleum Engineers. Paper SPE-107979-MS.

Raz, S. B., \& Ghassemi, A.. 2011. Stresses Around a Production Well In Gas HydrateBearing Formation. 45th US Rock Mechanics/Geomechanics Symposium, San Francisco, California. American Rock Mechanics Association. Paper ARMA-11-540.

Roussel, N. P.. 2011. Stress reorientation in low permeability reservoirs. SPE Reservoir Simulation Symposium, Houston, Texas, USA. Society of Petroleum Engineers. Paper SPE-173220-MS.

Roussel, N. P., \& Sharma, M. M. 2011. Strategies to minimize frac spacing and stimulate natural fractures in horizontal completions. SPE Annual Technical Conference and Exhibition, Denver, Colorado, USA. Society of Petroleum Engineers. Paper SPE146104-MS.

Rutqvist, J., R., Antonio P, \& Cappa, F., et al. 2015. Modeling of fault activation and seismicity by injection directly into a fault zone associated with Hydraulic fracturing of shale-gas Reservoirs. Journal of Petroleum Science and Engineering, 127: 377386.

Wan R.F., \& Luo Y.J.. 1989. Production Technical Manual (Volume 9). Beijing: Petroleum Industry Press.

Wang D. B. 2013. Study on the mathematical model about the fiber temporary plugging diverting fracturing crack initiation and propagation of the vertical wells. Master Thesis, Chengdu University of Technology, Chengdu, China.

Wang, D. B., Ge, H. K., \& Wang X. Q., et al. A novel experimental approach for fracability evaluation in tight gas reservoirs. Journal of Natural Gas Science \& Engeering, 2015, 23: 239-249, doi:10.1016/j.jngse.2015.01.039.

Wang, D.B., Zhou, F.J., \& Ding W., et al. A numerical simulation study of fracture reorientation with a degradable fiber-diverting agent. Journal of Natural Gas Science \& Engeering, 2015, 25: 215-225, doi: 10.1016/j.jngse.2015.05.002.

Wang Y.C., Jiang B.W., \& Ma Y.F., et al. 2005. Study of repeated fractruing technology in low-permeability sand oil reservoir in ansai oilfeild. Oil Drilling \& Production Technology, 27(5): 78-80.

Wang, W. D., Su, Y. L., Sheng, G. L., \& Manuel, Cossio. 2015. A mathematical model considering complex fractures and fractal flow for pressure transient analysis of 
fractured horizontal wells in unconventional oil reservoirs. Journal of Natural Gas Science \& Engineering. 23: 139-147.

Warpinski, N. R., Mayerhofer, M. J, \& Vincent, M. C., et al. 2009. Stimulating unconventional reservoirs: maximizing network growth while optimizing fracture conductivity. Journal of Canadian Petroleum Technology, 48(10): 39. Society of Petroleum Engineers. Paper SPE-114173-MS.

Warpinski N. R., Branagan, P. T.. 1989. Altered-stress fracturing. Journal of Petroleum Technology, 41(9): 990 - 997. Society of Petroleum Engineers. Paper SPE-17533-PA.

Weng D.W., Lei Q., \& Xu Y., et al. 2011. Network fracturing techniques and its appl ication in the field. ACTA PETROLEI SINICA, 32(2): 280-284.

Saheb, D. N., \& Jog, J. P., 1999. Natural fiber polymer composites: a review. Advances in polymer technology, 18(4): 351-363.

Shan X.J., Zhang S.C., \& Li A.Q., et al. 2005. Analyzing the fracture extended law of hydraulic fracturing in coal bed gas wells. Natural Gas Industry, 25(1): 130-132.

Shi Y., Zhou F.J., \& Yang X.Y., et al. 2013. Laboratory Study and Field Application of Fiber-Based Fracture Reorientation Technology. IPTC 2013: International Petroleum Technology Conference, Beijing, China. Society of Petroleum Engineers. Paper IPTC-16736-MS.

Vincent, M. C. 2011. Restimulation of unconventional reservoirs: when are refracs beneficial?. Journal of Canadian Petroleum Technology, 50(6): 36-40.

Yudin, A, Butula, K, \& Novikov, Y. 2007. A Novel Approach to Fracturing Height Control Enlarges the Candidate Pool in the Ryabchyk Formation of West Siberia's Mature Oilfields. European Formation Damage Conference, Scheveningen, The Netherlands. Society of Petroleum Engineers. Paper SPE-107604-MS.

Zhang H., Liu H.S., \& Wang J.Y., et al. 2005. Research and its application on fluid loss additive of HL-05 used for fracture transforming infracture reservoir. Drilling \& Production Technology, 28(5): 105-107.

Zhang J.C.. Numerical simulation of hydraulic fracturing coal bed methane reservoir. Fuel, 2014, 136: 57-61.

Zhang Y., Yang S.L., \& Jiao K.B.. 2014. Technology Research About Super Large Composite Acid Fracturing Filtration in Tahe Oilfield. Journal of Southwest Petroleum University (Science \& Technology Edition), 36(3): 121-126.

Zhou, F. J., Liu, Y. Z., \& Liu, X. F., et al. 2009. Case study: YM204 obtained high petroleum production by acid fracture treatment combining fluid diversion and fracture reorientation. 8th European Formation Damage Conference, Scheveningen, The Netherlands. Society of Petroleum Engineers. Paper SPE-121827-MS. 
Zhou F.J., Yi X.Y., \& Yang X.Y., et al. 2014. Dynamic filtration experiment of fiber temporary pluggin artificial fracture. Drilling \& Production Technology, 37(4): 83-86. doi: 10. 3969 /J. ISSN. 1006-768 X. 2014. 04. 26.

Zhou J., Chen M., \& Jin Y., et al. 2008. Analysis of fracture propagation behavior and fracture geometry using a tri-axial fracturing system in naturally fractured reservoirs. International Journal of Rock Mechanics and Mining Sciences, 45(7): 1143-1152.

Zhou J., Jin Y., \& Chen M.. 2010. Experimental investigation of hydraulic fracturing in random naturally fractured blocks. International Journal of Rock Mechanics and Mining Sciences, 47(7): 1193-1199. 


\section{TABLES AND FIGURES}

Table 1. The list of filtration coefficient of each core sample

\begin{tabular}{|c|c|c|c|c|c|c|c|}
\hline \multirow{2}{*}{$\begin{array}{c}\text { core } \\
\text { number }\end{array}$} & \multirow{2}{*}{$\begin{array}{l}\text { fracture } \\
\text { width } \\
(\mathrm{mm})\end{array}$} & \multicolumn{2}{|c|}{$\begin{array}{l}\text { filtration } \\
\text { coefficient } \\
\left(\mathrm{m} / \mathrm{min}^{1 / 2}\right)\end{array}$} & \multirow{2}{*}{$\begin{array}{c}\text { filtration coefficient ratio } \\
\text { between slickwater and } \\
\text { DCF }\end{array}$} & \multirow{2}{*}{$\begin{array}{l}\text { fracture } \\
\text { conductivity } \\
(\mathrm{mD} \cdot \mathrm{mm})\end{array}$} & \multirow{2}{*}{$\begin{array}{l}\text { fiber cake } \\
\text { permeability } \\
\quad(\mathrm{mD})\end{array}$} & \multirow{2}{*}{$\begin{array}{l}\text { fracture permeability } \\
\text { before DCF injection } \\
(\mathrm{mD})\end{array}$} \\
\hline & & $\begin{array}{c}\text { slick } \\
\text { water }\end{array}$ & $\mathrm{DCF}$ & & & & \\
\hline$\# 1$ & 0.21 & 0.0853 & 0.0233 & 3.661 & 37238.41 & I & 3675000 \\
\hline$\# 2$ & 1.51 & 4.56 & 1.25 & 3.648 & 203727.7 & 1349.2 & 190008333.3 \\
\hline \#3 & 2.52 & 4.859 & 1.776 & 2.736 & 66867180 & I & 529200000 \\
\hline$\# 4$ & 3.54 & 5.463 & 3.049 & 1.792 & I & I & 1044300000 \\
\hline
\end{tabular}




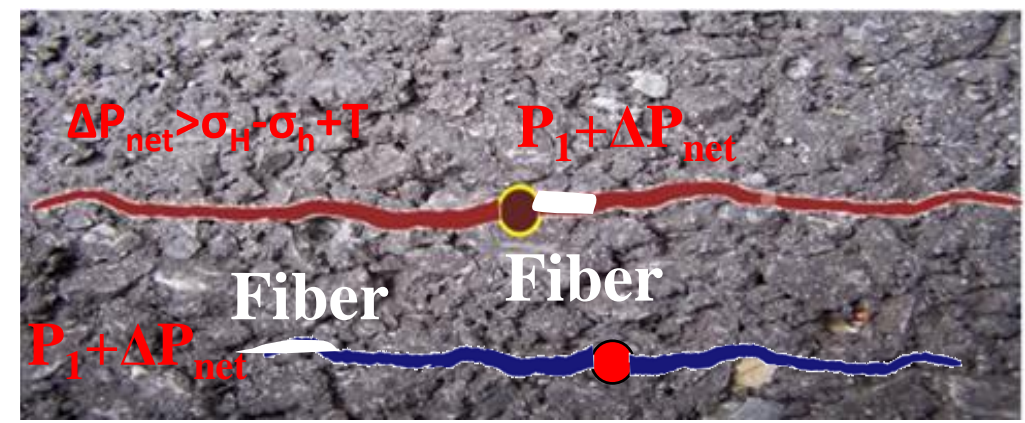

(a)

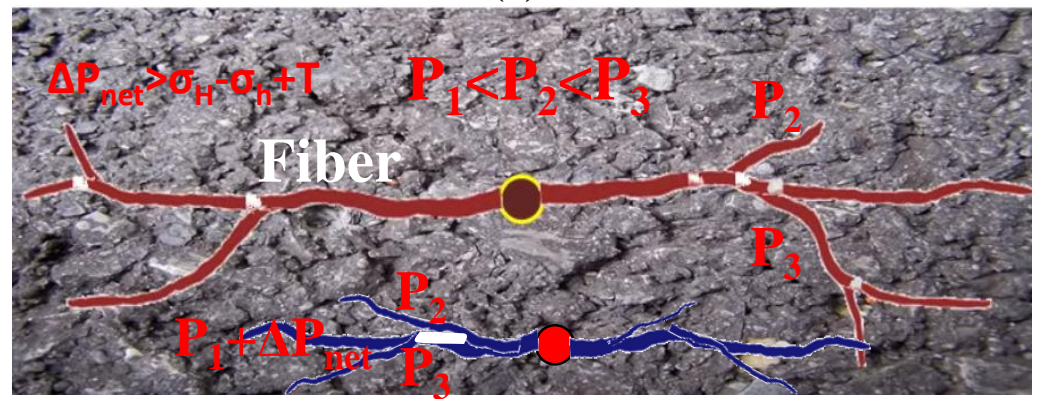

(b)

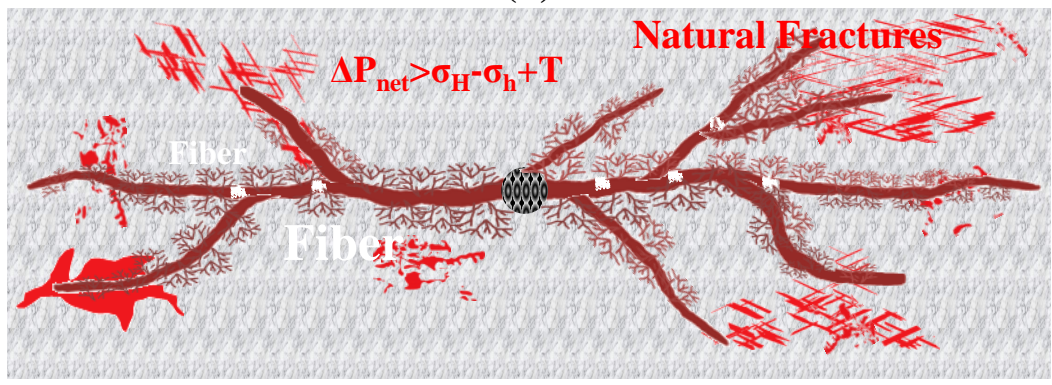

(c)

Fig. 1. Sketch map of mechanical mechanism of fiber-assisted diverting fracturing, where $\mathrm{P}_{1}, \mathrm{P}_{2}$ and $\mathrm{P}_{3}$ denotes the fracturing pressure of each fracture; $\Delta \mathrm{P}_{\text {net }}$ denotes the increase of net pressure caused by injecting fiber fluids; $\sigma_{\mathrm{H}}$ and $\sigma_{\mathrm{h}}$ denote the maximum and minimum horizontal principal stresses, respectively; and $\mathrm{T}$ denotes the tensile strength of rock. The condition $\mathrm{P}_{1}<\mathrm{P}_{2}<\mathrm{P}_{3}, \Delta \mathrm{P}_{\text {net }}>\sigma_{\mathrm{H}}-\sigma_{\mathrm{h}}+\mathrm{T}$ is satisfied. (a) Under the condition of a single fracture extension, fiber cake can effectively block the open mouth or tip of preexisting fractures. (b) describes the competition cracking of a multi-fracture with different fracturing pressures. After injecting fracturing fluids, new fractures will initiate and propagate in the order of minimum to maximum fracturing pressure. (c) describes the fracture diversion of inhomogeneous and anisotropic rock, opening new fractures. If the net pressure satisfies the equation $\Delta \mathrm{P}_{\text {net }}>\sigma_{\mathrm{H}}-\sigma_{\mathrm{h}}+\mathrm{T}$, and other factors such as the local stress field and weak plane meet certain mechanical conditions, new fractures will be generated. 


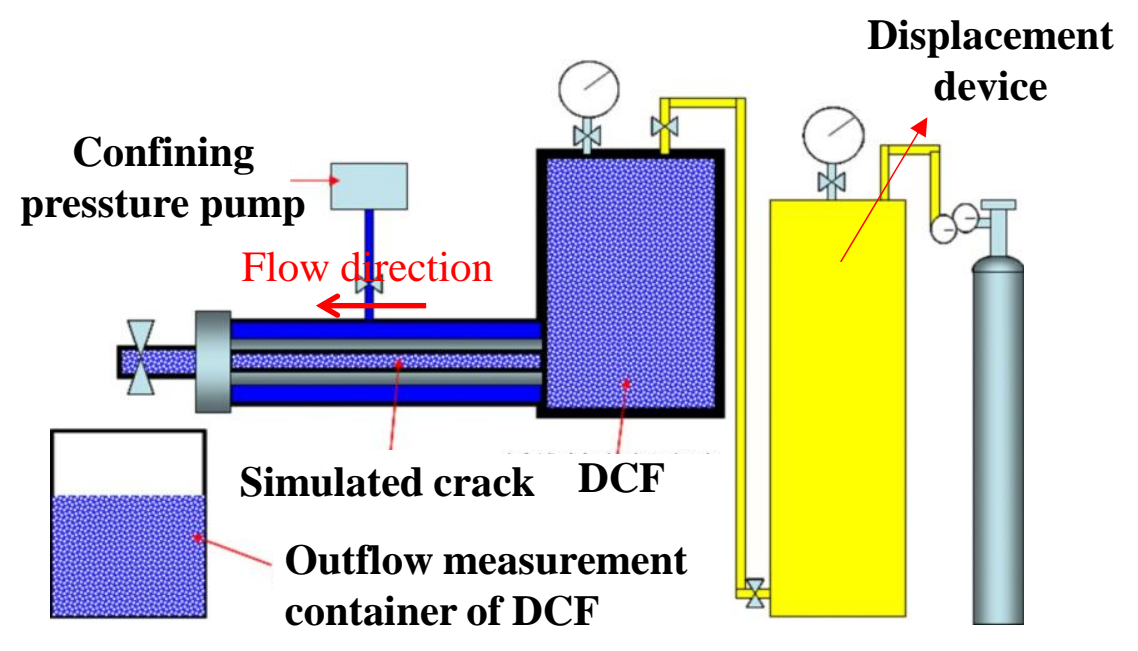

(a)

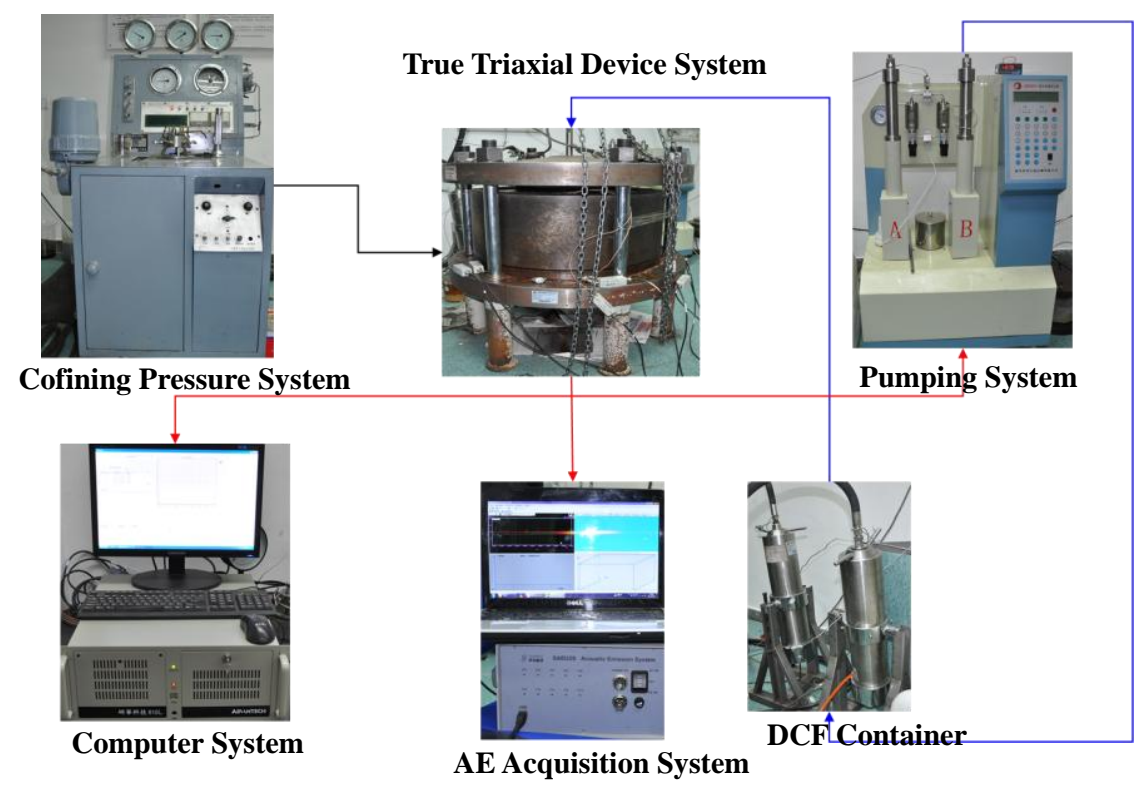

(b)

Figure 2. Schematic map of experimental set-up: (a) experimental device of fiber temporarily blocking artificial fracture and (b) true triaxial simulation test device for hydraulic fracturing. 


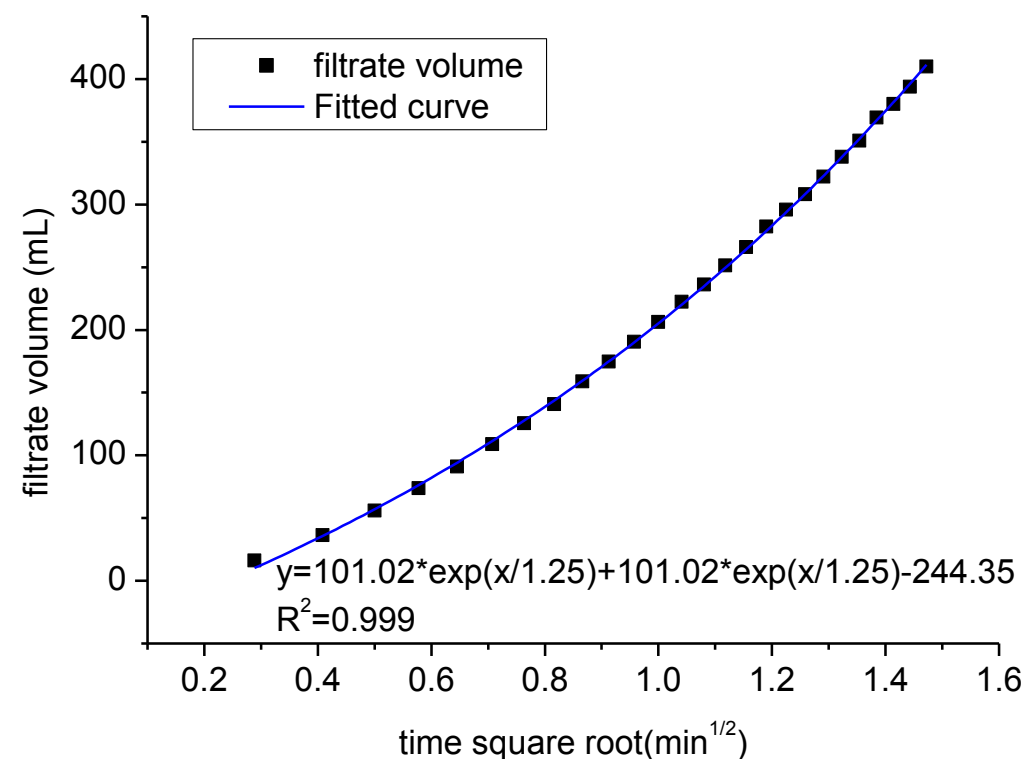

(a)

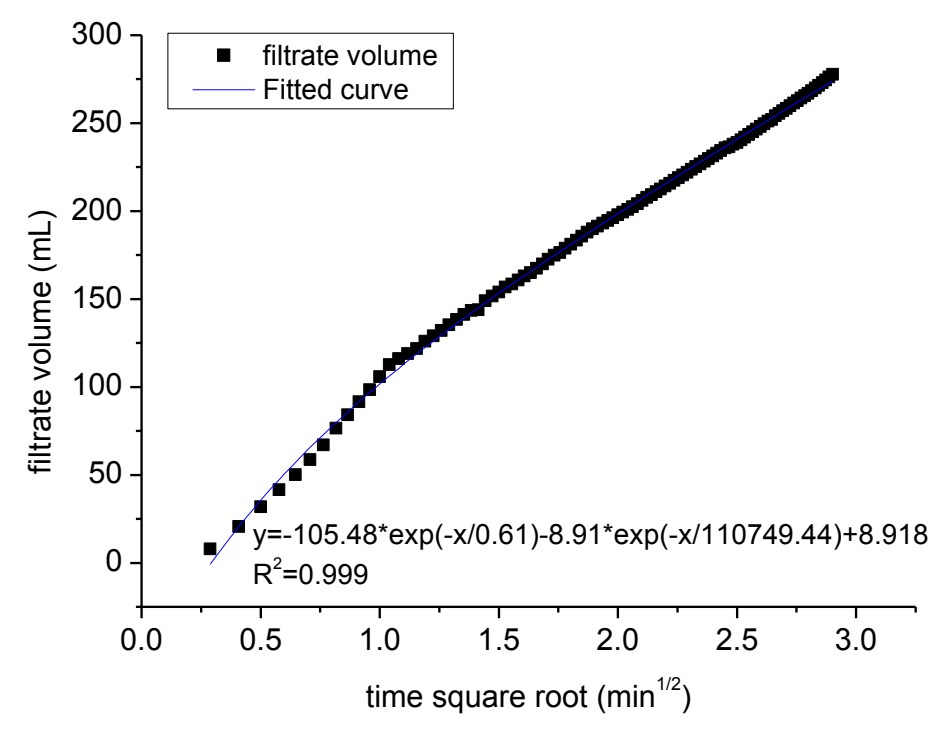

(b)

Figure 3. The filtration curves of slick water and DCF for \#1 core sample: (a) slick water; (b) DCF. The filtration coefficient is determined by the equation $\mathrm{C}=0.005 * \mathrm{~m} / \mathrm{A}$ according to the oil industry standard of China (SYT5107-2005). C denotes the filtration coefficient; $m$ denotes the slope of fitting curves; and A denotes filtration area. The bigger the slope $\mathrm{m}$ is, the bigger the filtration coefficient $\mathrm{C}$ is (Zhou et al, 2014). 


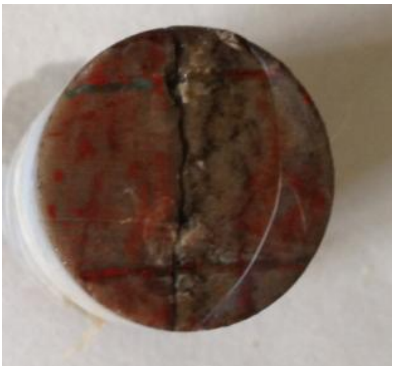

(a)

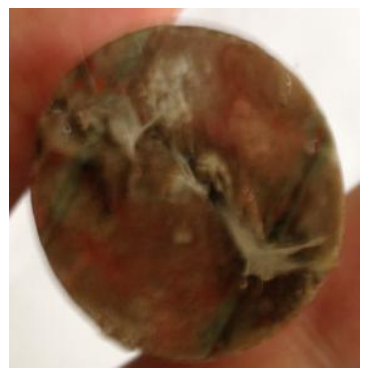

(c)

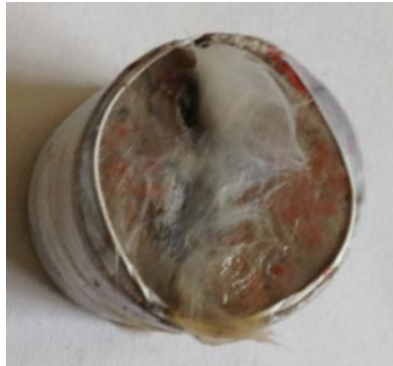

(b)

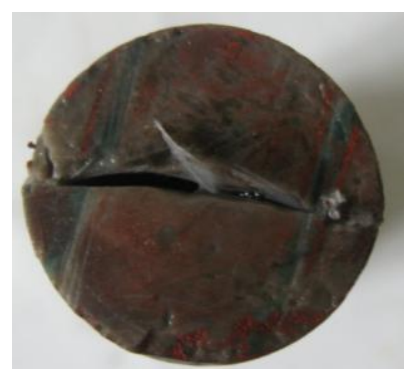

(d)

Figure 4. Fiber filter cake of each core sample: (a) Core sample \#1 does not form a fiber cake because of its narrow fracture width; (b) Core sample \#2 includes a good fiber cake; (c) Core sample \#3 forms a small amount of fiber cake; (d) Core sample \#4 forms a tiny amount of fiber cake (Zhou et al., 2014). Experimental conditions are all the same: a speed of $2 \mathrm{r} / \mathrm{min}$, a pumping rate of $0.5 \mathrm{~mL} / \mathrm{min}$, and a confining pressure of $5 \mathrm{MPa}$. The fiber concentration in the experiments is $1 \% \mathrm{wt}$. 


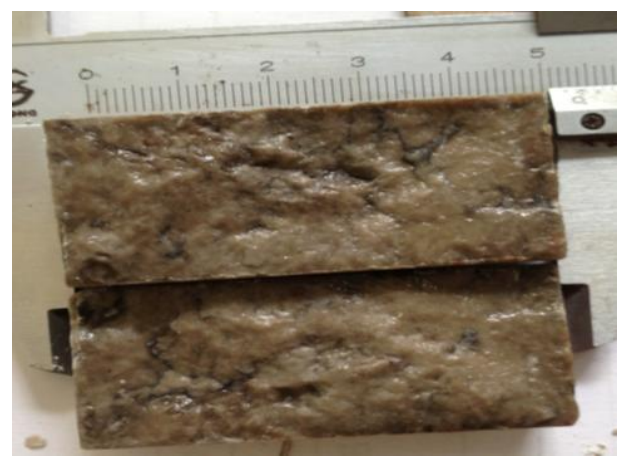

(a)

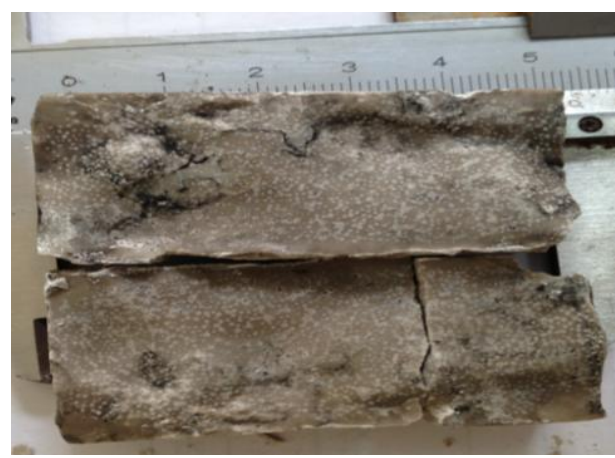

(c)

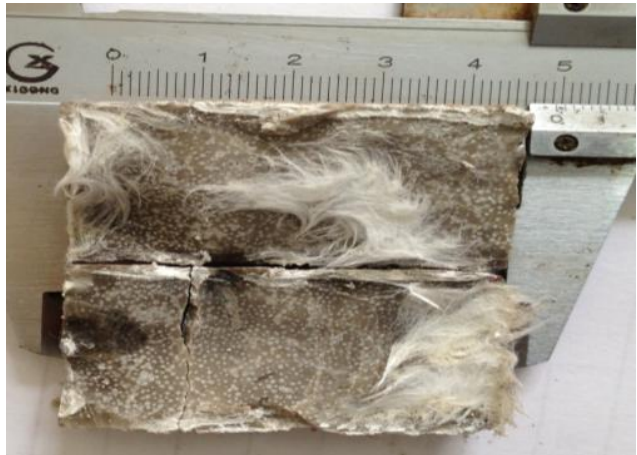

(b)

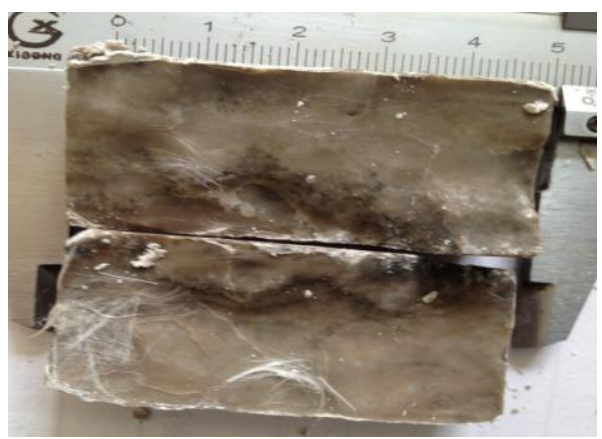

(d)

Figure 5. Fiber cake of each opened core sample after conductivity experiments: (a) Core sample \#1 does not form a fiber cake; (b) Core sample \#2 includes a good fiber cake; (c) The formed fiber cake of core sample \#3 in Fig. 4c is taken away by fluid; (d) Core sample \#4 forms a tiny amount of fiber cake. 


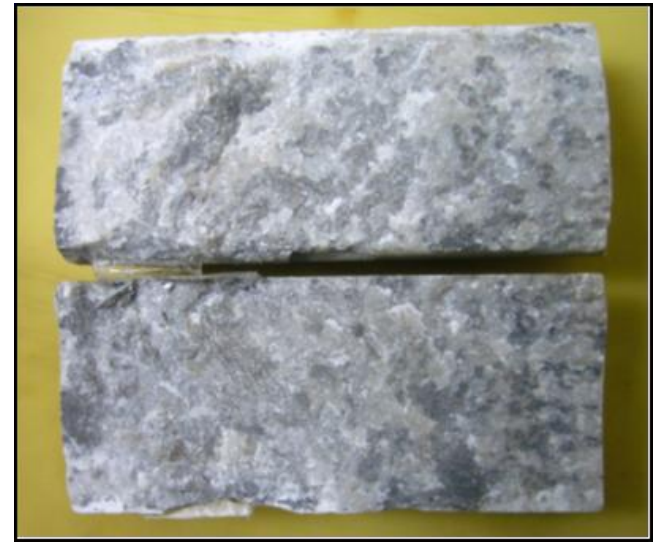

(a)

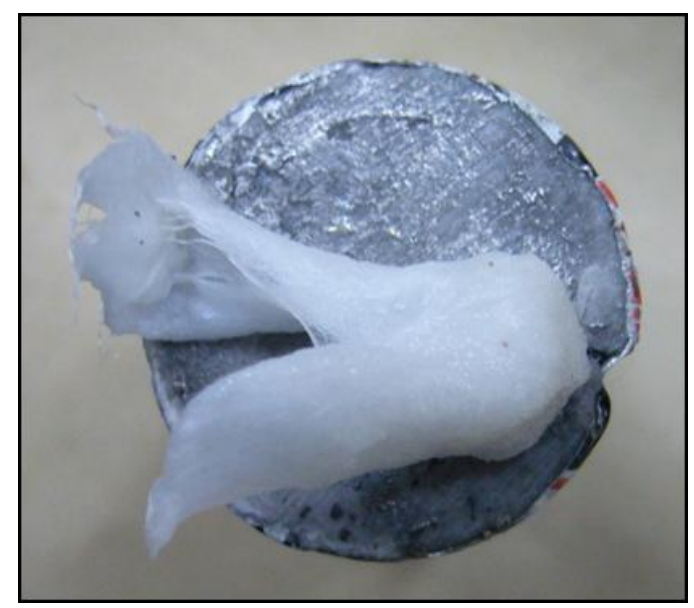

\section{(b)}

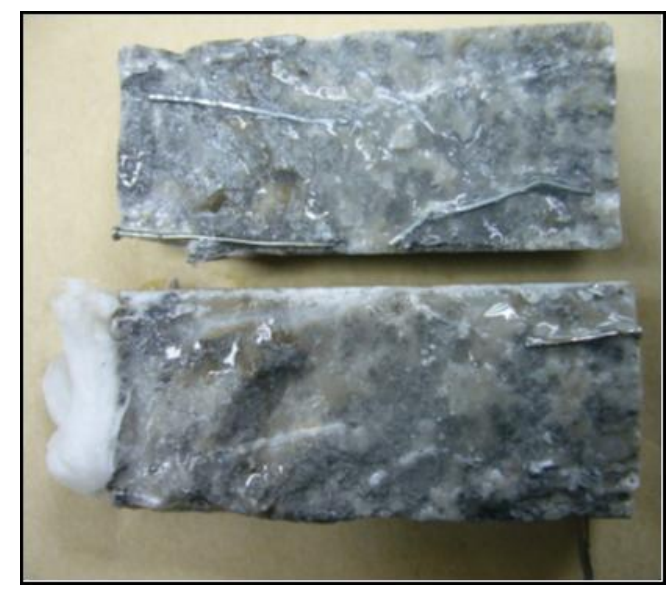

Figure 6. The diagram of fiber bridging state for the core sample in $0.5 \mathrm{~mm}$ width: (a) before temporary plugging; (b) after temporary plugging. 


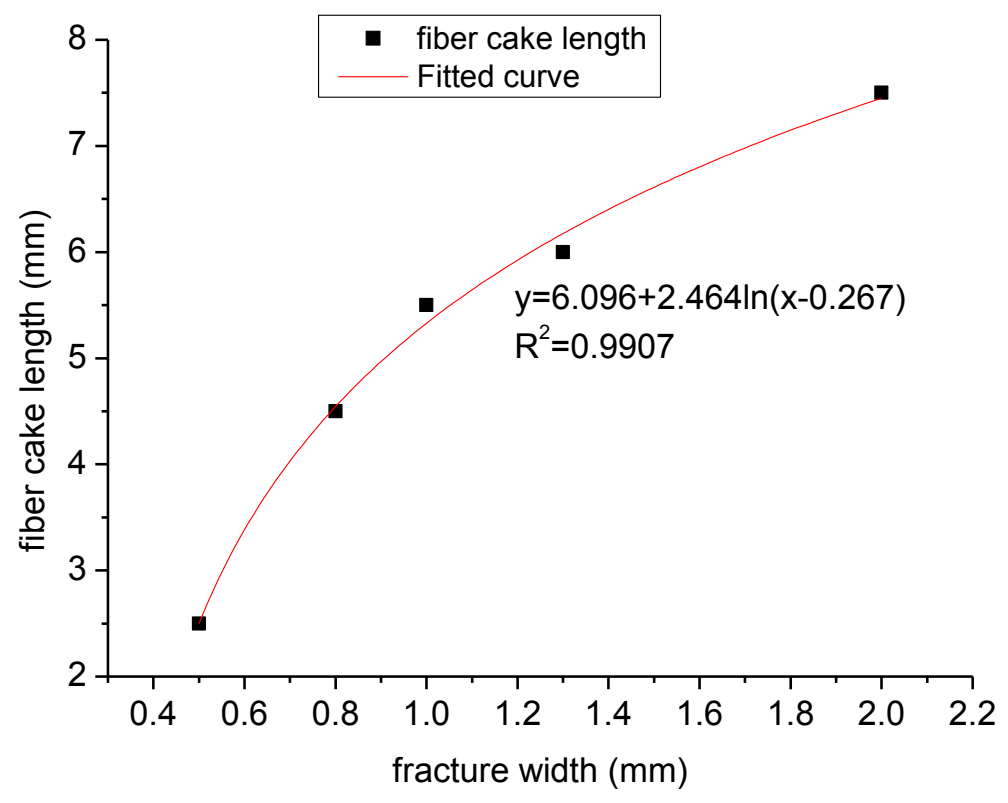

Figure 7. Regressed correlations between fracture width and fiber cake invasion length. $x$ denotes the average fracture width, and y denotes the invasion length of fiber cake. Their units are both in mm (millimeters). 


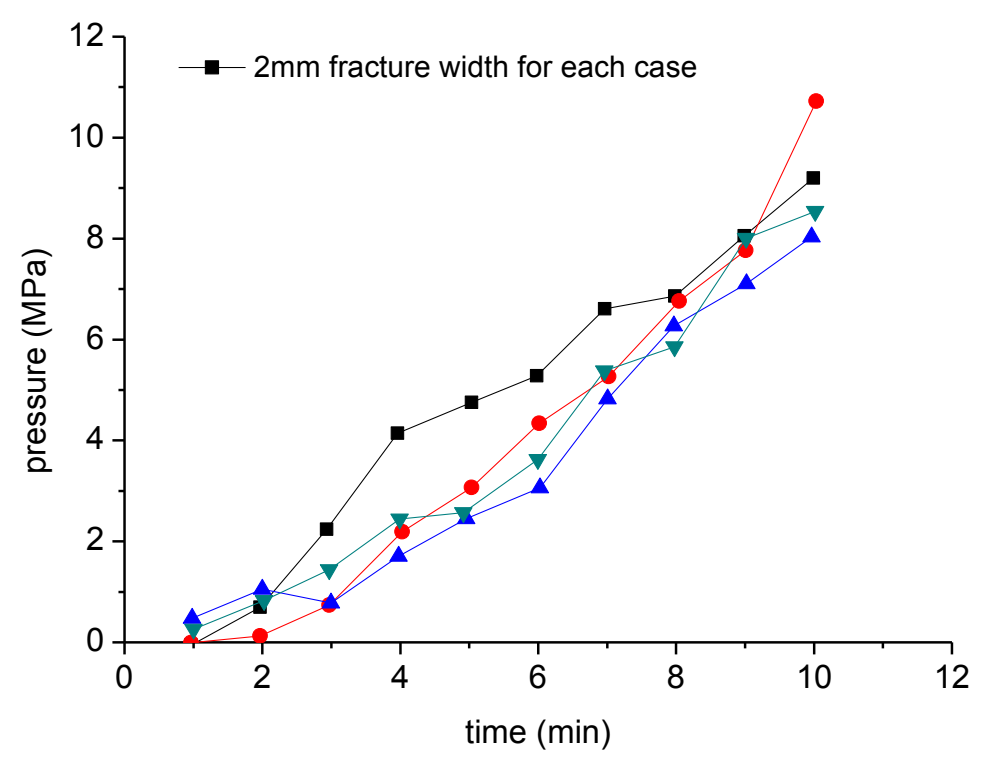

(a)

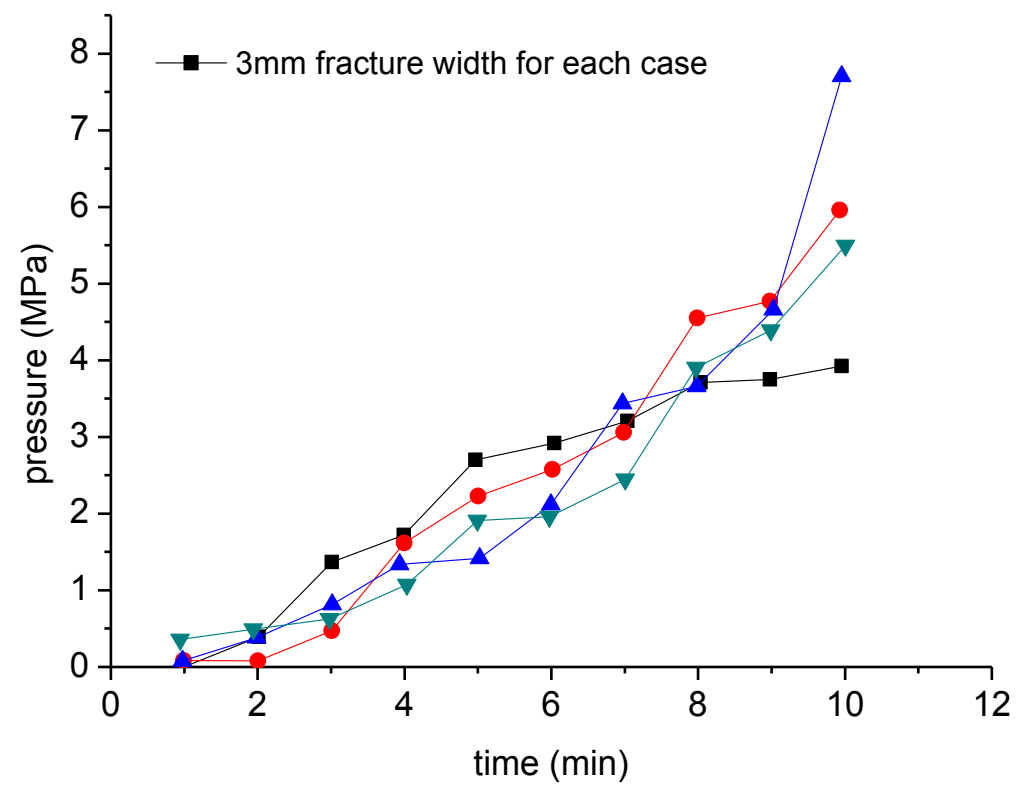

(b)

Figure 8. Curve of fiber blocking fracture ability at different fracture width levels: (a) pressure change curve with time, simulated fracture height $20 \mathrm{~mm}$, fracture width $2 \mathrm{~mm}$, injection rate of $0.5 \mathrm{~L} / \mathrm{min}$; (b) pressure change curve with time, simulated fracture height $20 \mathrm{~mm}$, fracture width $3 \mathrm{~mm}$, injection rate of $0.5 \mathrm{~L} / \mathrm{min}$. 


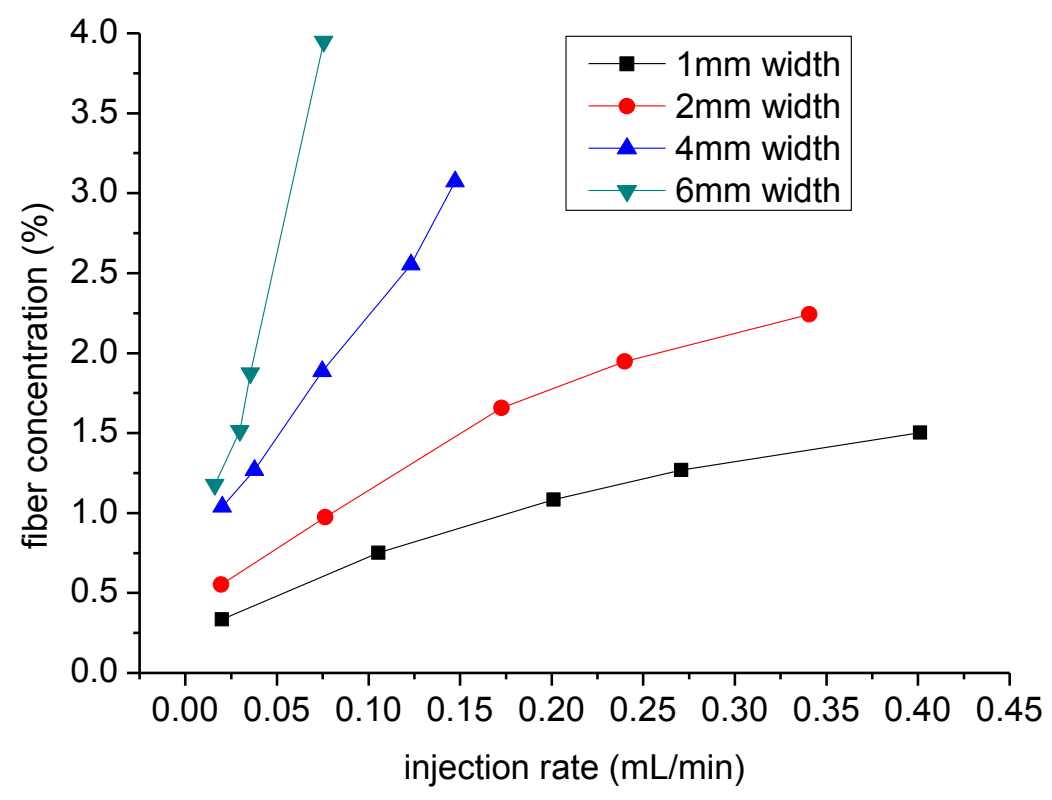

Figure 9. The relationship curve between injection rate and critical fiber concentration of different fracture widths.

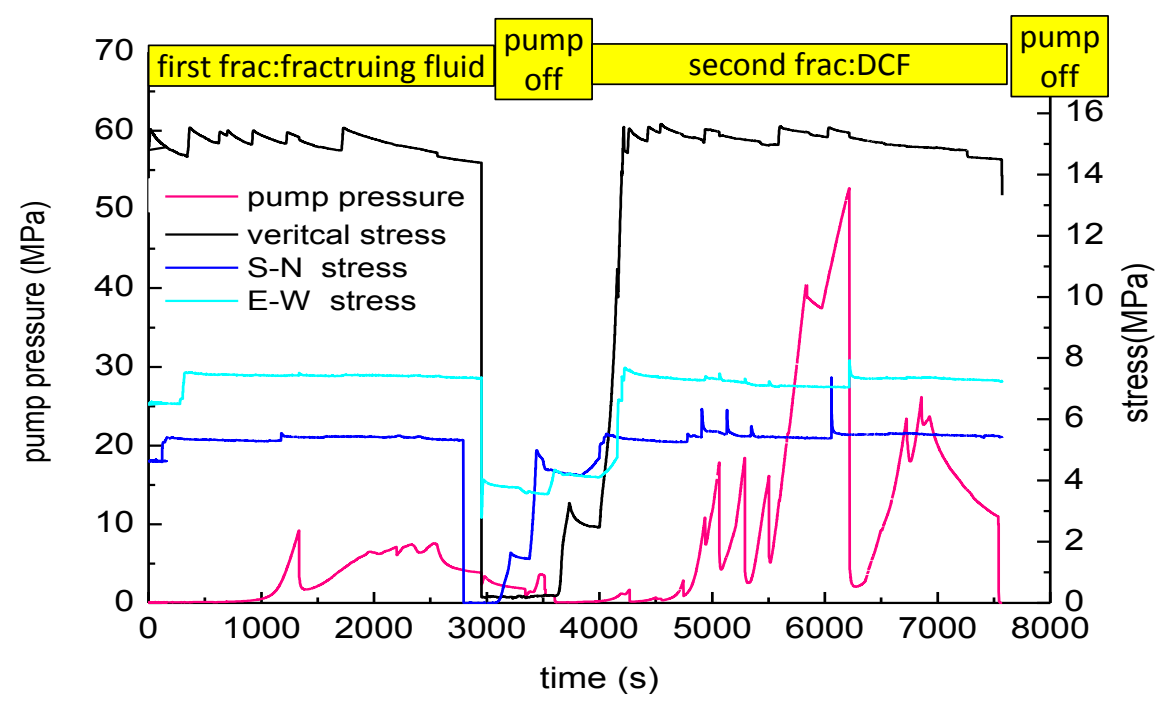

(a) 


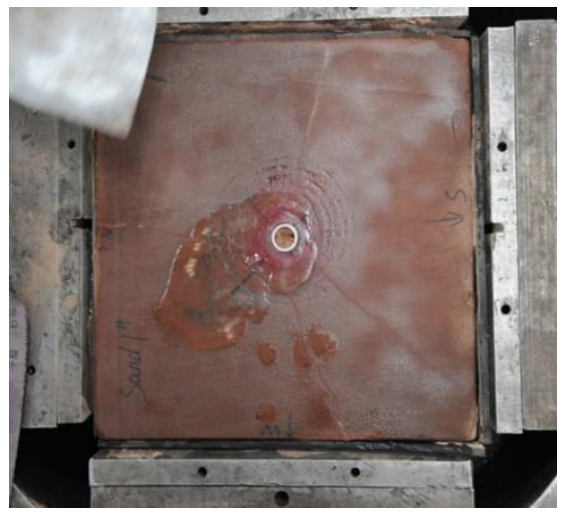

(b)

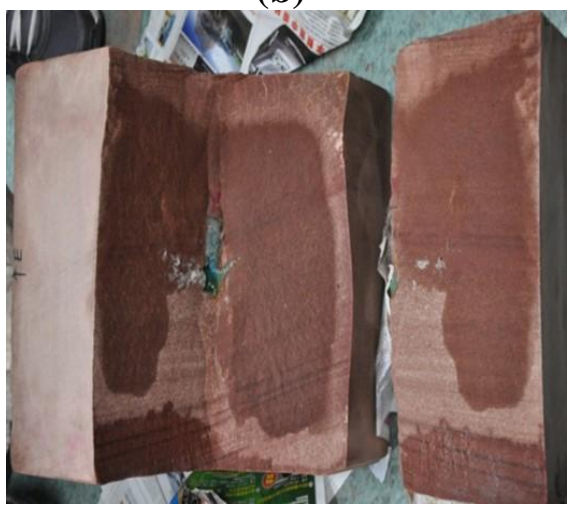

(d)

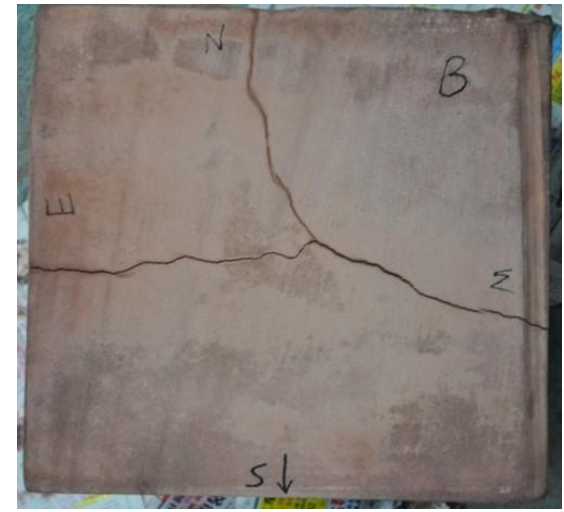

(c)

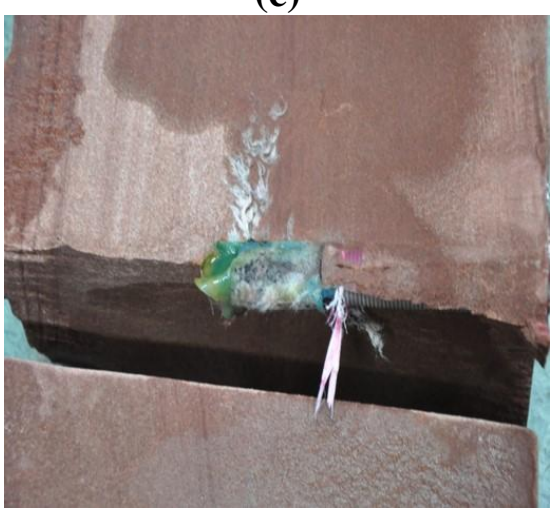

(e)

Figure 10. Experimental results of Sandstone \#2 core sample: (a) pump pressure change curves at different period time. (b-e) $\Delta \sigma=2.5 \mathrm{MPa}, \sigma_{h}=5 \mathrm{MPa}, \sigma_{H}=7.5 \mathrm{MPa}, \sigma_{V}=15 \mathrm{MPa}$; figure(b-c) demonstrate that: a single fracture in the east is observed along the maximum horizontal stress direction after the first fracturing; after the second fracturing, new fractures are approximately perpendicular to the first one; figure(d-e) show that formed fiber cake is good for temporary plugging fracture. The block is a sandstone outcrop from Xinjiang Province, northwest China. Its size is $300 \mathrm{~mm} * 300 \mathrm{~mm} * 300 \mathrm{~mm}$. The fiber cake is colored in green.

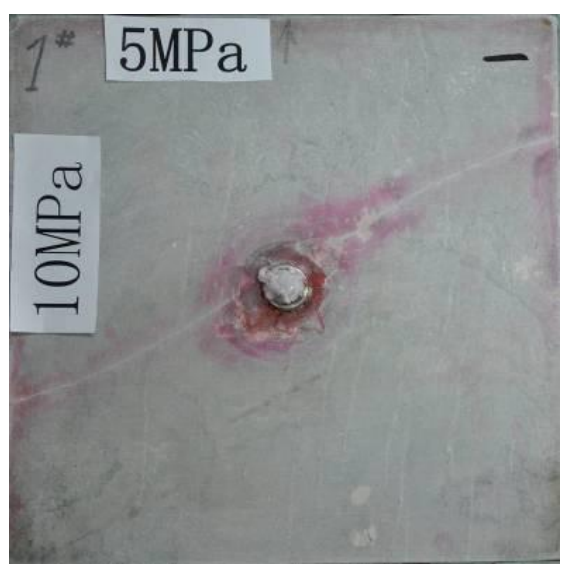

(a)

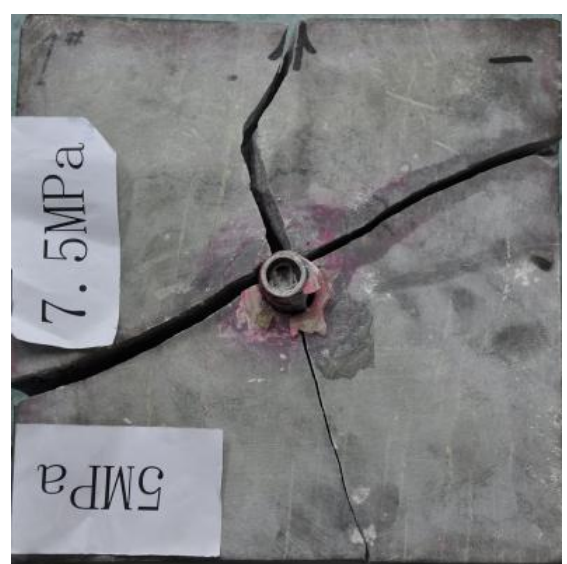

(b) 


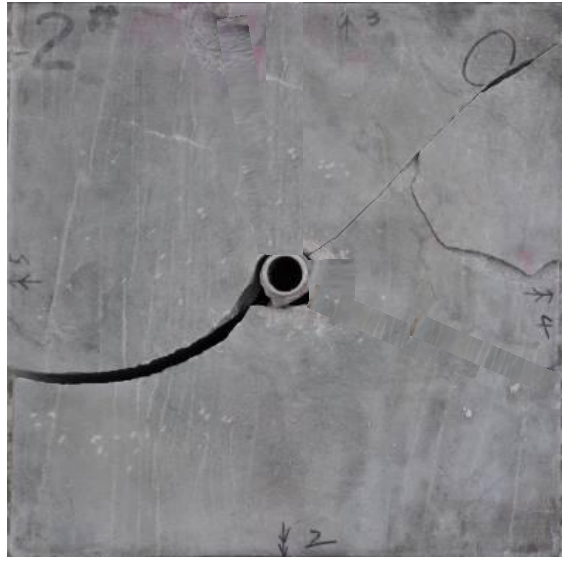

(c)

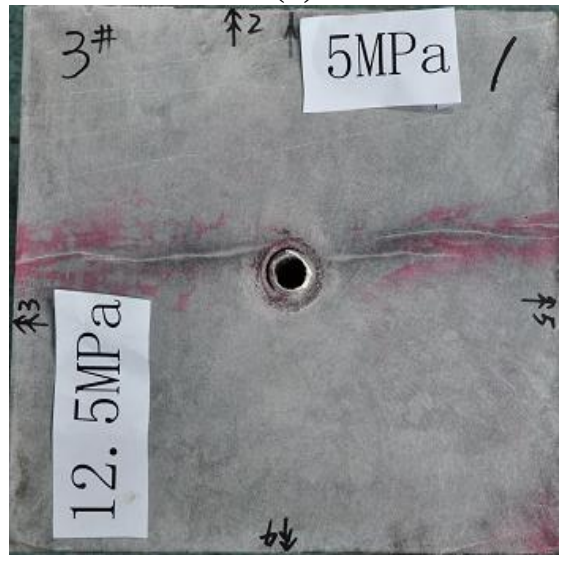

(e)

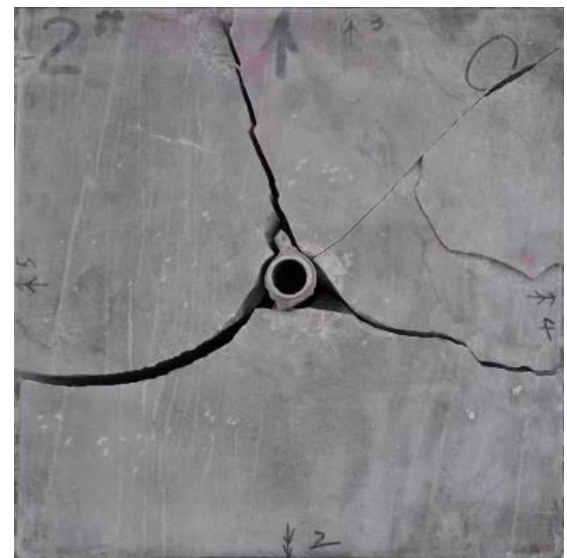

(d)

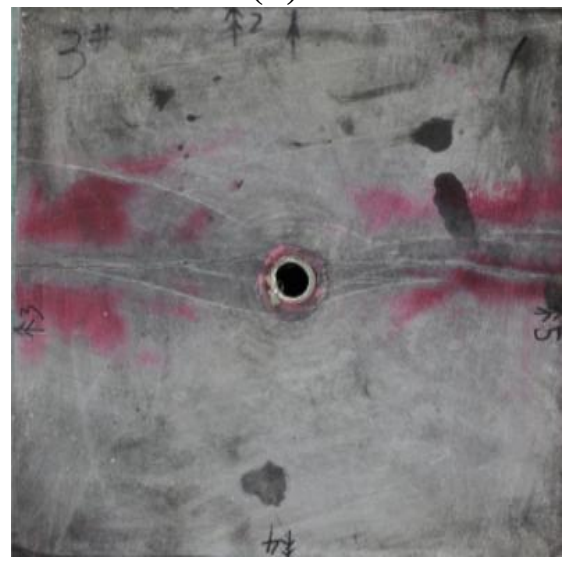

(f)

Figure 11. Experimental results of fracture reorientation with fiber-diverting agent: $(a-b)$ Sample \#1, $\Delta \sigma=2.5 \mathrm{MPa}, \sigma_{h}=5 \mathrm{MPa}, \sigma_{H}=7.5 \mathrm{MPa}, \sigma_{V}=10 \mathrm{MPa}$; (c-d) Sample \#2, $\Delta \sigma=$ $5.0 \mathrm{MPa}, \sigma_{h}=5 \mathrm{MPa}, \sigma_{H}=10 \mathrm{MPa}, \sigma_{V}=15 \mathrm{MPa}$; (e-f) Sample \#3, $\Delta \sigma=7.5 \mathrm{MPa}, \sigma_{h}=5$ $\mathrm{MPa}, \sigma_{H}=12.5 \mathrm{MPa}, \sigma_{V}=18 \mathrm{MPa}$;. The left figure represents the artificial fracture morphology after the first fracturing, and the right figure represents the diverting fracture morphology after the second fracturing. 


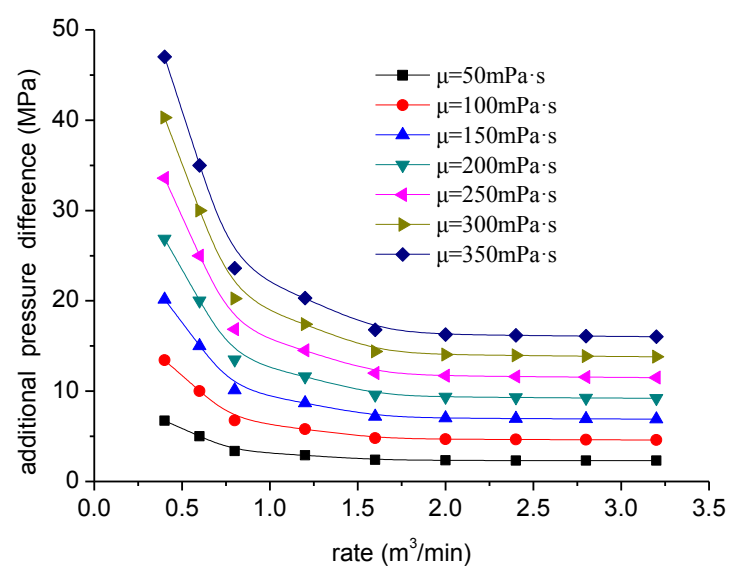

(a)

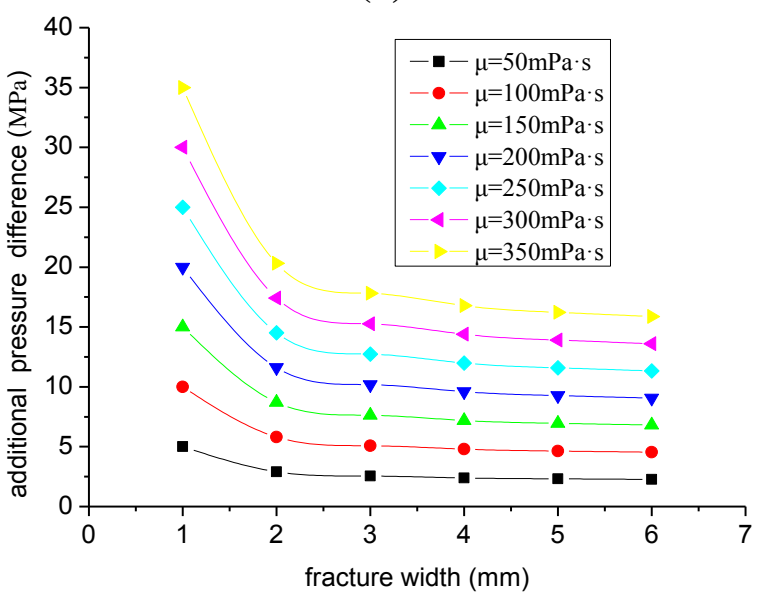

(b)

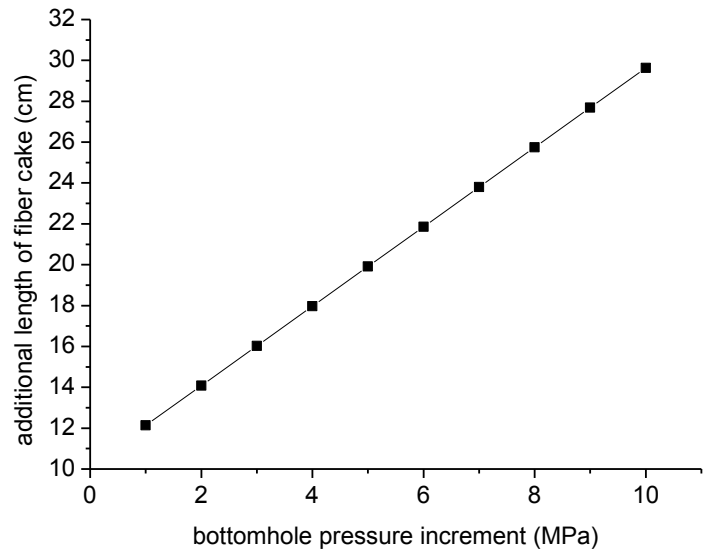

(c)

Figure 12. Factor sensitivity analysis of additional pressure drop of fiber cake: (1) pumping rate; (b) fracture width; (c) botomhole pressure increment. 


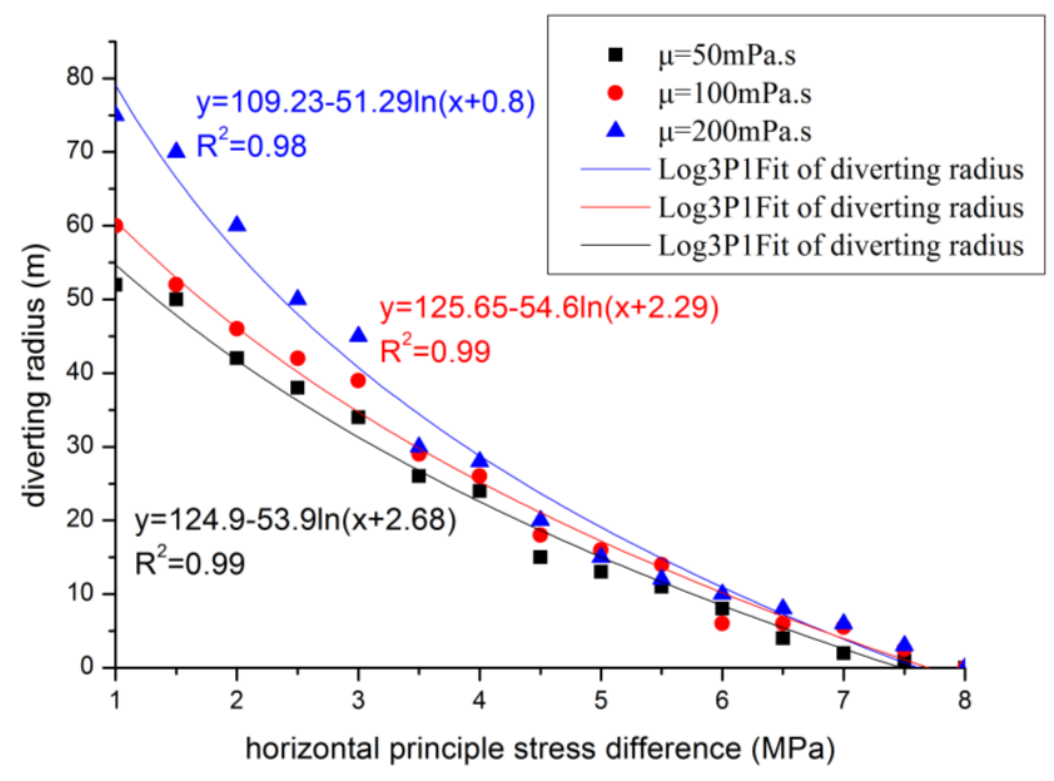

Figure 13. Regressed correlations between stress difference and diverting radius at different viscosity levels in the physical simulating experiment of fiber-laden diverting fracturing (Wang et al., 2015).

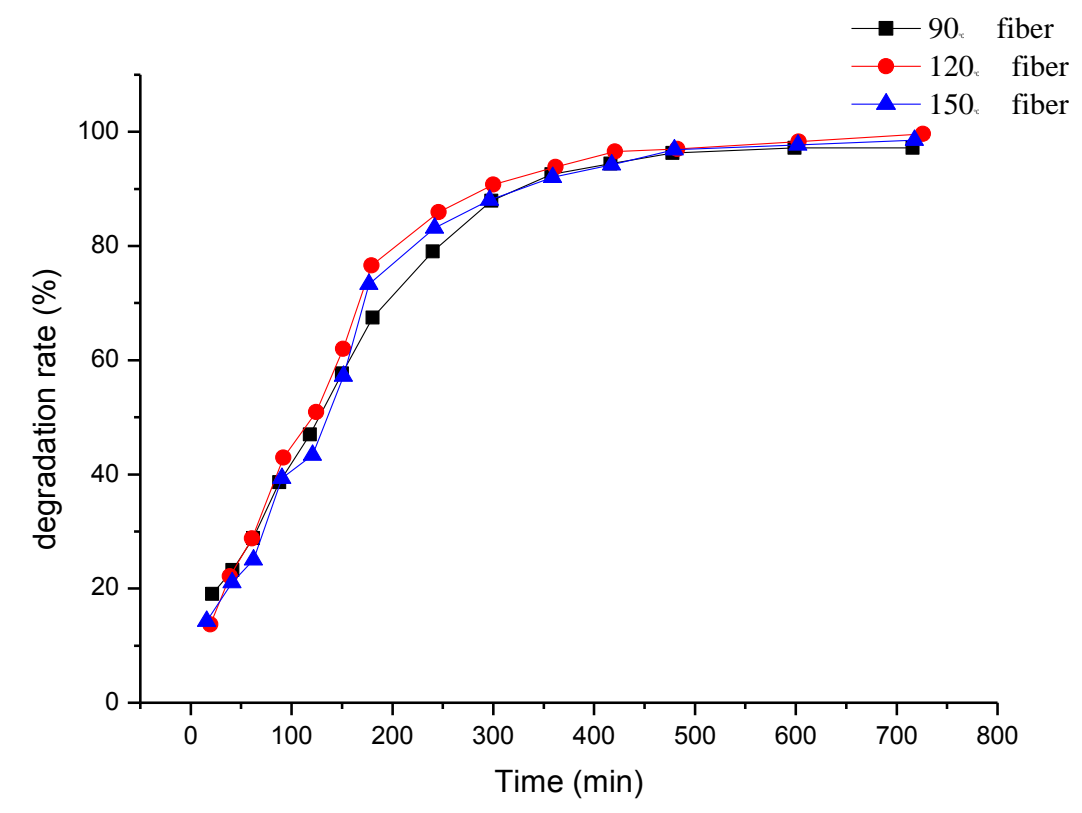

Figure 14. The degradation rate curve of three different kinds of fibers 